OPEN ACCESS

Edited by:

Liam Chen,

University of Minnesota, United States

Reviewed by:

Emanuele La Corte,

University of Bologna, Italy

Güliz Acker,

Charité Medical University of Berlin,

Germany

*Correspondence:

Ping Zhong

zhp228899@163.com Bin Wang

wangbin@huashan.org.cn

${ }^{\dagger}$ These authors have contributed equally to this work and share first authorship

Specialty section:

This article was submitted to Neuro-Oncology and

Neurosurgical Oncology, a section of the journal

Frontiers in Oncology

Received: 27 June 2021 Accepted: 06 September 2021 Published: 27 September 2021

Citation:

Zhang Y, Long J, Ren J, Huang X, Zhong $P$ and Wang $B$ (2021)

Potential Molecular Biomarkers of Vestibular Schwannoma Growth:

Progress and Prospects.

Front. Oncol. 11:731441. doi: 10.3389/fonc.2021.731441

\section{Potential Molecular Biomarkers of Vestibular Schwannoma Growth: Progress and Prospects}

\author{
Yu Zhang ${ }^{1 \dagger}$, Jianfei Long ${ }^{1 \dagger}$, Junwei Ren ${ }^{2}$, Xiang Huang ${ }^{2}$, Ping Zhong ${ }^{2 *}$ and Bin Wang ${ }^{1 *}$ \\ ${ }^{1}$ Department of Pharmacy, Huashan Hospital, Fudan University, Shanghai, China, ${ }^{2}$ Department of Neurosurgery, Huashan \\ Hospital, Fudan University, Shanghai, China
}

Vestibular schwannomas (VSs, also known as acoustic neuromas) are relatively rare benign brain tumors stem from the Schwann cells of the eighth cranial nerve. Tumor growth is the paramount factor for neurosurgeons to decide whether to choose aggressive treatment approach or careful follow-up with regular magnetic resonance imaging (MRI), as surgery and radiation can introduce significant trauma and affect neurological function, while tumor enlargement during long-term follow-up will compress the adjacent nerves and tissues, causing progressive hearing loss, tinnitus and vertigo. Recently, with the deepening research of VS biology, some proteins that regulate merlin conformation changes, inflammatory cytokines, miRNAs, tissue proteins and cerebrospinal fluid (CSF) components have been proposed to be closely related to tumor volume increase. In this review, we discuss advances in the study of biomarkers that associated with VS growth, providing a reference for exploring the growth course of VS and determining the optimal treatment strategy for each patient.

Keywords: vestibular schwannoma, growth, biomarker, target therapy, merlin

\section{INTRODUCTION}

VSs are histologically benign lesions deriving from the Schwan cells of the vestibulo-cochlear nerve commonly occur unilaterally, or bilaterally in the pathognomonic for the hereditary disorder neurofibromatosis type 2 (NF2) $(1,2)$. Generally, the mere presence of benign tumors is not a therapeutic indication. However, the slow but progressive growth of this intracranial tumor can confer compression to adjacent cranial nerve and brainstem, resulting in neurological deficits, balance difficulty and sensorineural hearing loss (SNHL) (3).

The goal of VS treatment has shifted from saving lives towards functional preservation, with multifaceted decision including watch-wait-rescan protocol, surgical resection and radiation $(4,5)$. However, surgery can be traumatic (6), while radiotherapy has a low hearing retention rate and can affect neurological function even after many years (7). We can see from the literature that two-thirds of VS did not grow during 3.6 years of follow-up, the average growth rate of sporadic VS was 1.1 $\mathrm{mm}$ /year diameter, and for NF2-related tumors $1.7 \mathrm{~mm} /$ year $(8,9)$, supporting the wait and watch policy in appropriate patients. A study showed that conservative management in small- to mediumsized VS (less than $2 \mathrm{~cm}$ ) can improve rates of facial nerve preservation and hearing protection in comparison to patients who undergo primary surgical treatment (10). Therefore, for stable or 
involuting tumors with no mass effect, or elderly patients who will suffer higher risk of comorbidities, the continuing trend toward observation with regular follow-up imaging is reasonable $(5,11)$.

Nevertheless, observation policy carries the inherent risk of tumor progression and hearing deterioration in growing tumors, which emphasizing the importance of the identification of effective and convenient indicators to predict growth characteristics at the time of diagnosis to weigh the benefits and risks of active treatment against watchful observation. Previous studies have reported onset at an early age, increasing size in the first year, hearing loss, extrameatal tumor location, cerebellopontine angle extension, sway velocity with eyes open were risk factors for tumor growth $(9,12-15)$. Here, we provide a narrative review on the topic of biomarkers currently considered to be related to VS growth in order to assist surgeons to select the most accurate treatment approach and the development of innovative targeted therapies.

\section{METHODS}

The authors conducted a literature review using Web of Science and PubMed databases in order to identify important recent publications and synthesized them into a comprehensive review of potential biomarkers of VS growth. The search strategy included the search terms "growth", "expression" and "vestibular schwannoma". We have also scanned the reference lists of published articles for further potential hits of relevance to this review. Peer-reviewed full articles published in English till August 2021 were included to compile this review. Search results were judged for relevance by the research team using the title, abstract and if necessary full text. Studies were included, if they 1) explored the relationship between biomarkers and the size or growth of sporadic VS or NF2-associated VS; 2) explored molecules that aberrantly expressed in VS compared with normal tissues; 3) drug research for VS treatment. Studies were excluded, if they 1) merely found some imaging manifestations or clinical features related to VS growth; 2) case reports.

\section{RESULTS}

We summarized the search results into five major types of biomarkers, which are summarized in Table $\mathbf{1}$.

\subsection{Merlin Pathway Related Proteins}

Neurofibromin 2 gene mutation and the function loss of its transcription protein merlin (an acronym for moesin-ezrinradixin-like protein) are widely regarded to play a paramount role in the pathogenesis of both sporadic and bilateral VS (46, 47). Merlin belongs to the ERM (for ezrin, radixin, moesin) family of cytoskeleton linker proteins and shares a common structural organization with it: a relatively conserved $\mathrm{N}$-terminal FERM domain, followed by a $\alpha$-helical region and a charged hydrophilic-COOH terminal tail (48). The neurofibromin 2 gene encodes for two major isoforms of merlin: exon 16 skipping production isoform 1 and exon 16 retention isoform 2, both of which carry full tumor suppressive function (49).

Merlin maintains the stability of the cell membrane by the binding of integral membrane proteins and spectrin actin cytoskeleton and mediates cell contact inhibition (50). Merlin exerts its growth suppressive function by modulating the activity of intracellular promitogenic signal cascades related to tumor

TABLE 1 | Summary table of potential biomarkers related to VS growth.

\begin{tabular}{|c|c|c|c|}
\hline Major types & $\begin{array}{l}\text { Action } \\
\text { mechanisms }\end{array}$ & Biomarkers and their characteristics & Referenc \\
\hline \multirow{7}{*}{$\begin{array}{l}\text { Merlin } \\
\text { pathway } \\
\text { proteins }\end{array}$} & RTK signal proteins & VEGF expression was increased in VS, and anti-VEGF therapy was effective for NF2-VS. & (16) \\
\hline & & Pharmaceutical inhibition of PDGFR could reduce VS growth rate. & $(17,18)$ \\
\hline & & bFGF promoted proliferation and invasion of VS cells, and also might be a hearing protector in VS. & $(16,19)$ \\
\hline & & ErbB family proteins were aberrantly expressed in VS, and its inhibition has therapeutic effects on VS. & $(20)$ \\
\hline & Ras signal proteins & Merlin inhibits Ras signal transduction by interfering with GRB2 expression and inhibiting Rac1 and PAK1 activation. & $(21-23)$ \\
\hline & $\begin{array}{l}\text { CPI-17-MYPT1 } \\
\text { switch }\end{array}$ & CPI-17-MYPT1 switch was responsible for the conformational change of merlin. CPI-17 was over-expressed in VS. & $(24-26)$ \\
\hline & $\begin{array}{l}\text { Hippo signal } \\
\text { proteins }\end{array}$ & $\begin{array}{l}\text { Merlin activated LATS1/2 and inhibited the destabilization of LATS1/2 by CRL4 }{ }^{\text {DCAF1 }} \text {. LATS1/2 promoted the } \\
\text { degradation of YAP and inhibited the transcription of pro-proliferation and anti-apoptotic genes stimulated by YAP. }\end{array}$ & $(27,28)$ \\
\hline \multirow[t]{2}{*}{$\begin{array}{l}\text { Inflammatory } \\
\text { signal }\end{array}$} & Local inflammation & $\begin{array}{l}\text { The NF-kB signal activated in VS was considered to be the core of VS pathophysiology. } \\
\text { COX-2 was highly expressed in VS and was associated with high proliferation rate. }\end{array}$ & $\begin{array}{l}(29,30) \\
(31)\end{array}$ \\
\hline & $\begin{array}{l}\text { Systemic } \\
\text { inflammation }\end{array}$ & $\begin{array}{l}\text { Macrophages, especially M2-type macrophages, were thought to promote VS growth. } \\
\text { High NLR was associated with VS growth. }\end{array}$ & $\begin{array}{l}(32,33) \\
(34)\end{array}$ \\
\hline \multirow{5}{*}{$\begin{array}{l}\text { Tumor } \\
\text { miRNAs } \\
\text { Tumor } \\
\text { proteins }\end{array}$} & $\begin{array}{l}\text { Gene expression } \\
\text { regulation }\end{array}$ & $\begin{array}{l}\text { The upregulation of miR-29abc, miR-19, miR-340-5p, miR-21, miR-221 and downregulation of miR-744, let-7b } \\
\text { were related to VS growth velocity. }\end{array}$ & $(35,36)$ \\
\hline & Glycoprotein & CD105 can be used as a MVD marker, and was correlated with VS size and growth rate. & (37) \\
\hline & Neurotrophic factor & BDNF expression was correlated with mitotic activity in VS. & $(38)$ \\
\hline & Proteases & $\begin{array}{l}\text { The expression of MMP-2 and MMP-9 was correlated with VS growth rate and was higher in cystic VS than solid } \\
\text { VS. The proteolytic activity of MMP-14 was related to the degree of SNHL in VS patients. }\end{array}$ & $(39-41)$ \\
\hline & & The expression of ADAM9 was higher in VS and related to functional impairment. & $(42,43)$ \\
\hline \multirow{2}{*}{$\begin{array}{l}\text { CSF } \\
\text { components }\end{array}$} & Mucopolysaccharide & HA levels were elevated in NF2-VS and correlated with the proliferation rate of schwannoma cells. & $(44)$ \\
\hline & Proteins & ABCA3, SCG1, KLF11, CA2D1, BASP1and PRDX2 were associated with VS growth. & $(45)$ \\
\hline
\end{tabular}


formation, including Ras/Raf/MEK/ERK (51), PI3K/Akt (52), c-JNK (53), Hippo signaling pathway, and the overall activity of the $\mathrm{E} 3$ ubiquitin ligase CRL4 ${ }^{\mathrm{DCAF} 1}$ in the nucleus (54). Moreover, merlin was reported to assuming a possible role in the mediation of cell cycle progression (55).

Classically, it was considered that the activity of merlin was regulated by phosphorylation on the main regulatory $\operatorname{Ser}^{518}$ : dephosphorylated merlin functions as a growth inhibitor in a closed conformation formed by intramolecular association of its $\mathrm{N}$-terminal domain (NTD) and carboxy-terminal domain (CTD), while phosphorylated merlin cannot form a folded state and is functionally deficient (56). However, subsequent researches have shown that transcripts of the mutated neurofibromin 2 gene or phosphorylated merlin have a more closed form, leading to impaired contact-dependent inhibition of proliferation $(57,58)$. There is also a controversial view holding that merlin's tumor suppressive function is independent of its conformational change (59). The activation of receptor tyrosine kinases (RTKs), integrins, CD44 and cadherin signal are responsible for the regulation of merlin's phosphorylation via the downstream effector p21-activated kinase 1 (PAK1) and myosin phosphatase targeting subunit 1 (MYPT1) (Figure 1) $(60,61)$.

\subsubsection{RTKs}

The over-expression and over-activation of at least four types of RTKs and their ligands involved in the progression or invasion of sporadic and NF2-associated VS: ErbB (62), platelet-derived growth factor (PDGF) (63), basic fibroblast growth factor (bFGF) (19) and vascular endothelial growth factor (VEGF) (64).

VEGF is one of the most prominent angiogenesis stimulator that can regulate irregular blood vessel sprouting and growth except for simple remodeling of the capillary basement membrane (65), and lead to development of an immuno suppressive tumor microenvironment (66). Compared with normal vestibular nerve, the expression of VEGF, VEGFR-1/Flt and VEGFR-2/Flk as well as the coreceptor NP1 were considerable increased in VS tissues, suggesting at least a part of neoplastic growth was induced via the promotion of angiogenesis $(39,64,67)$. Tissue microarray analysis of 182 sporadic VSs found significantly higher VEGF levels in the groups of recurrent and preoperatively irradiated tumors when compared to primary VS patients (67). However, there are contradictory views as to whether VEGF expression is correlated with sporadic VS growth characteristics. Koutsimpelas et al. initially found a positive correlation between VEGF expression and tumor volume, tumor growth index (calculated by dividing the maximal tumor diameter by the patient's age) and microvessel density (MVD, defined by CD31 staining) (16), but further investigation with expanded sample size demonstrated that although tumors with high proliferation index and high levels of VEGF and its receptor were more common than those with low proliferation activity expressing low levels of VEGF and its receptor, the expression of neither VEGF nor its receptors correlated with the proliferation indexes (Ki-67) or the growth characteristics of the tumors (67).

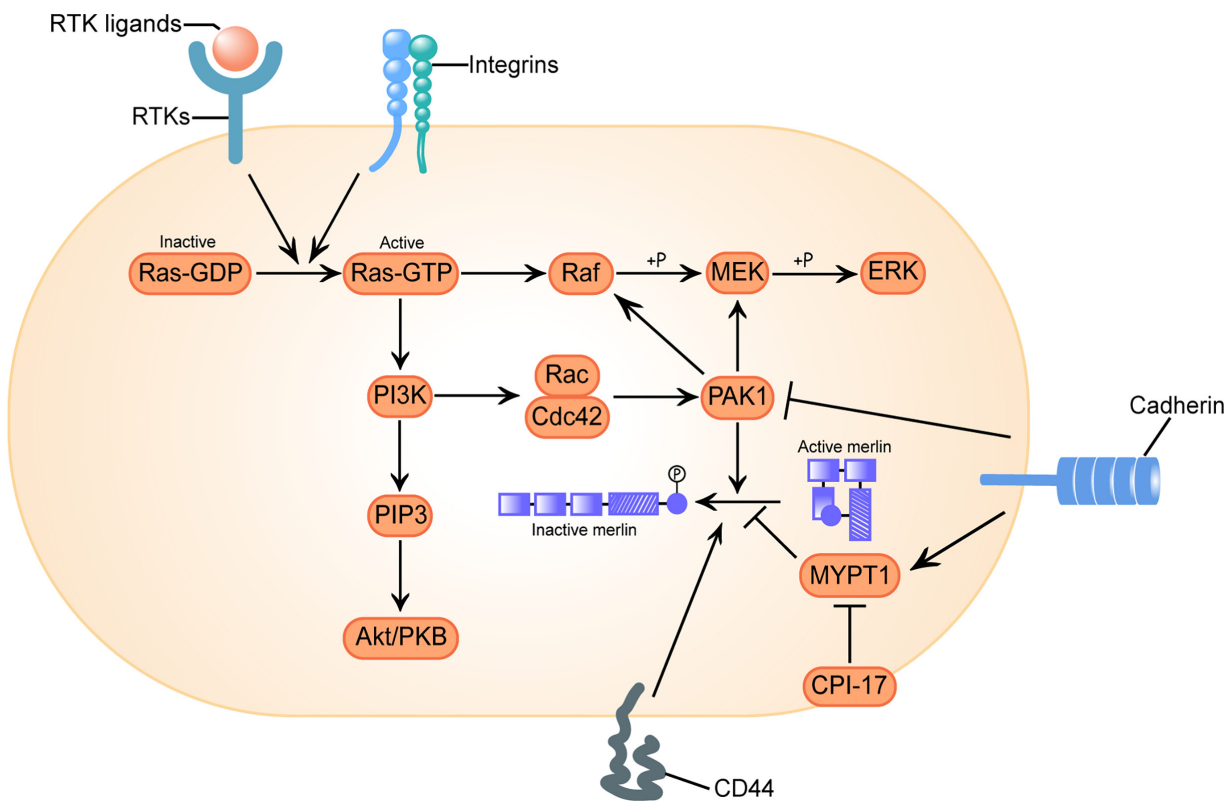

FIGURE 1 | Configurational changes of Merlin in response to receptor tyrosine kinases (RTKs), integrins, clusters of differentiation 40 (CD40) and cadherins signal stimulation. Activation of RTKs and integrins triggers GTP loading of Ras, which drives three mitogenic downstream pathways: Raf/MEK/ERK, PI3K/Rac/PAK, and PI3K/PIP3/Akt/PKB. p21-activated kinase 1 (PAK1) is an effector of the downstream pathway activated by Ras, which phosphorylates merlin at Ser ${ }^{518}$ and converts it to an inactive conformation. Conversely, myosin phosphatase targeting subunit 1(MYPT1) dephosphorylates and reactivates merlin. C-kinase potentiated protein phosphatase-1 inhibitor of $17 \mathrm{kDa}$ (CPI-17) acts as a cellular inhibitor of MYPT1, causes loss of function of merlin. CD44 inactivates merlin. Engagement of cadherins inactivates PAK1 and activates MYPT1, inducing merlin's tumor suppressor function in a two-fold way. Here we adopt the broadly accepted hypothesis that phosphorylated merlin is the inactive form. 
Multiple anti-VEGF therapy studies in patients with progressive NF2-VS have shown that bevacizumab can not only ameliorate hearing loss and reduce tumor size (68), but also normalize the tumor vasculature and reduce vasogenic edema, which improved the delivery of oxygenation, a potent radiosensitizer, and therefore reduced radiation dose and minimized radiation-related neurotoxicity (69).

As a regulator of cell growth and division, PDGF can regulate stemness in schwannoma cell lines and have a role in tumorigenesis (70). The PDGF family consists of five different disulphide-linked dimers built up of four different polypeptide chains encoded by four different genes. These isoforms, PDGF-AA, PDGF-AB, PDGF-BB, PDGF-CC and PDGF-DD, act via two RTKs, PDGF receptors $\alpha$ and $\beta$ (71). Nilotinib (17) and Gleevec (18, 63, 72) pharmacologically inhibit these two receptors and their main downstream signaling pathways that have been proved to be over-expressed and activated in VS, and could also potentially reduce the angiogenic activity and growth rate of VS.

bFGF (also known as FGF-2 or FGF- $\beta$ ) was not only an identified angiogenic cytokine (73), but also implicated in tumor maintenance and metastasis (74). bFGF was identified as a mediator to protect auditory neurons from acoustic trauma and aminoglycoside ototoxicity, it was 3.5-fold higher in good hearing VS versus poor hearing VS (75), and its plasma concentration increased while patient's hearing improved after bevacizumab regimen (76). bFGF is also a known mitogen that promotes the proliferation of cell cultures derived from sporadic VS and increased the invasive phenotype mediated by Akt and ERK in HEI-193 cells $(19,77)$. In sporadic VS, increased levels of bFGF were positively correlated with tumor volume, tumor growth index and MVD (16). The mechanism by which bFGF stimulates mitosis might divergent from the way it modulates hearing. This notion, together with the results of cytokine array analysis where levels of ErbB, a well-established growth modulator, are not correlate with hearing status, may partly explain the irrelevance of tumor growth rate or tumor volume with VS patients' hearing outcome (75).

The ErbB family consists of four members: ErbB-1/EGFR/Her1, ErbB-2/Neu/Her2/p185, ErbB-3/Her3, and ErbB-4/Her4. ErbB family is upregulated in many malignant tumors, and also aberrantly expressed in VS. It has been reported that $68 \%$ of EGFR (62\% sporadic and 75\% NF2-associated VS), 84\% of ErbB2 (76\% sporadic and 94\% NF2-related VS) and 34\% of ErbB3 were upregulated in VS (20). Of EGFR ligands, EGF was up-regulated in all NF2-related VS, but none of the sporadic VS; Neuregulin was up-regulated in $86 \%$ of sporadic VS and $19 \%$ of NF2-related VS (20). In HEI-193 cells, the addition of EGF increased cellular invasion by 10 -fold, which could be reduced by the inhibition of PI3K/Akt (19). Both dual small molecule inhibitor of EGFR and ErbB2 Lapatinib and the EGFR inhibitor Erlotinib demonstrated their therapeutic effects in VS (78-80).

\subsubsection{Ras and Related Raf/MEK/ERK, PI3K/Akt and Rac/PAK}

The small G-protein Ras, the downstream oncoprotein of RTKs that cycles between an inactive GDP-bound and an active GTP- bound state, play a role in the cascade of cell proliferation and division. In its active state, Ras can interact with several different effectors, thereby triggering an array of downstream signaling networks that responsible for promoting cellular transformation and driving tumorigenesis, such as Ras/Raf/MEK/ERK and Ras/ PI3K/Akt pathways (81-83). It is well known that activation of Ras leads to subsequent activation of Rac/Cdc42 and its downstream effector PAK1, whose phosphorylation of Raf on $\mathrm{Ser}^{338}$ and MEK on Ser ${ }^{298}$ is required for effective signal transfer of Ras (Figure 1) $(84,85)$.

An increasing body of literature suggests that merlin counteract Ras-induced transformation at multiple levels. Merlin interferes with the expression of endogenous growth factor receptor binding 2 (GRB2) protein (21), directly reduces the GTP-loading of Ras and Rac to restrain their activation (86), and directly binds to the 21 binding domain (PBD) of PAK1 to interrupt PAK1 activation and its recruitment to focal adhesions $(22,87)$. Merlin competitively binds to angiomotin and releases the Rac1 negative regulator Rich1, which ultimately attenuates Rac1 signaling (23). Dysfunction of merlin would allow for enhanced Ras signal transduction and accelerated tumor growth rate (24).

Merlin itself is regulated by PAK reciprocally, it was phosphorylated at $\mathrm{Ser}^{518}$ by active PAK and therefore lose the inhibition of cell transformation. Activated Rac expression induces merlin phosphorylation and decreases the association between merlin and cytoskeleton (60). Based on the study of the role of Ras pathway signal transduction in the growth of VS, preclinical assessment of PAK inhibitors (88), MEK1/2 inhibitors (81) and Ailanthone, the down regulator of Ras and Raf, all exhibited certain antitumor properties (89).

\subsubsection{MYPT1}

MYPT1 is a phosphatase that forms the C-kinase potentiated protein phosphatase-1 inhibitor of $17 \mathrm{kDa}$ (CPI-17)-MYPT1 switch along with its most specific and potent inhibitor CPI-17, regulating the phosphorylation of both merlin and other ERM family proteins $(24,90)$. Although highly homologous, the activity changes of merlin and other ERM proteins after C-terminal phosphorylation are opposite, and fulfils an antagonistic role in Ras activity control: the phosphorylation inactivates merlin, which counteracts Ras-induced transformation (91), but activates ERM proteins, which are essential for proper Ras activation (92). Thus, the oncogenic protein CPI-17 may activate Ras signaling in a two-fold way.

A previous systematically investigation on schwannomas showed that CPI-17 stained negative in non-tumor pathologies, but specifically up-regulated in over $90 \%$ of schwannomas, primarily in sporadic schwannomas (25). Moreover, high CPI-17 levels were found to correlate with higher Ki-67 proliferation indices, indicating a putative role of CPI-17 in schwannoma progression (25). Xu et al. found the over-expression of CPI-17 was a prominent feature of sporadic VS tissues, and there was a significantly positive correlation between CPI-17 expression and merlin phosphorylation (26), confirming the rationality of the causal chain CPI-17-MYPT1-merlin dysfunction in VS. 


\subsubsection{Yes-Associated Protein (YAP)}

The deregulation of the Hippo pathway and the accompanying activation of Yes-associated protein (YAP) has been implicated in VS cell proliferation (27). As described in Figure 2, merlin initiate Hippo pathway to promote the phosphorylation and degradation of YAP and its homologous protein transcriptional coactivator with PDZ-binding motif (TAZ) $(93,94)$. In the inactivated state of merlin, YAP/TAZ migrates into the nucleus and binds to TEA domain family members (TEAD), stimulating the transcription of pro-proliferation and anti-apoptotic genes $(27,95)$.

The E3 ubiquitin ligase CRL4 ${ }^{\mathrm{DCAF} 1}$ can directly ubiquitinylate and destabilize LATS1/2 to activate YAP (54). Merlin can translocates into the nucleus, binds with high affinity to CRL4 ${ }^{\mathrm{DCAF} 1}$ and blocks its function (28). It is postulated that this merlin-CRL4 ${ }^{\mathrm{DCAF} 1}$-LATS1/2-YAP signaling axis might be the key mechanism of merlin's tumor suppressive effect. Although no studies have directly confirmed the correlation between VS tumorigenesis and CRL4 ${ }^{\mathrm{DCAF} 1}$ activity, targeted inhibition of the upstream activator of CRL4 ${ }^{\mathrm{DCAF} 1}$, NEDD8-activating enzyme (NAE), can induce inhibitory YAP phosphorylation and reduce cell proliferation in mouse neurofibromin 2-mutant schwannoma cells and human neurofibromin 2-mutant mesothelioma cell line (96), indicating a growth-promoting role of CRL4 ${ }^{\text {DCAF1 }}$ in neurofibromin 2-inactivated tumors.

\subsection{Inflammatory Signal}

At present, there is increasing evidence that a variety of solid tumors contain a certain degree of tumor-associated inflammation that play a role in the cancer formation, progression and metastasis (97). Inflammatory response in cancer patients comprises both the local inflammatory response and the systemic response. The local inflammatory response is mediated by chemokines, cytokines, growth factors and matrix metalloproteinases (MMPs) secreted from in situ tumor cells, stromal cells, and infiltrating immune cells, and can became accomplices to cancer development by enhancing cell survival, invasion, neovascularization, and adaptive immunity suppression (98). Meanwhile, inflammation in the tumor microenvironment could be reflected in peripheral circulation, i.e., systemic inflammatory response that characterized by white cell components in peripheral blood, such as the platelet-tolymphocyte ratio (PLR) and neutrophil-to-lymphocyte ratio (NLR), which have been highlighted as probable markers of pathologic responses for numerous types of solid tumors $(99,100)$.

It has been demonstrated that the volume increase of VS is not merely based on cell proliferation, but is also implicated with (neo)vascularization, intratumoral hemorrhage, cyst formation and inflammatory reaction $(32,101,102)$.

FIGURE 2 | Schematic diagram of merlin and Hippo pathway signaling. On the one hand, merlin initiates the Hippo pathway by directly activating mammalian STE20-like protein (MST1/2), which in turn phosphorylates large tumor suppressor homolog 1/2 (LATS1/2), or by recruiting LATS 1/2 to the plasma membrane for phosphorylation by MST1/2 kinases. The activated LATS1/2 directly phosphorylates Yes-associated protein (YAP) at Ser ${ }^{397}$ and transcriptional coactivator with PDZbinding motif (TAZ) at Ser ${ }^{311}$, priming the neighboring phosphodegron motif for phosphorylation by CK1 $1 / \mathrm{\epsilon}$ kinases and multi-level control of YAP/TAZ levels. In parallel, merlin also translocates to the nucleus and blocks the activity of the nuclear E3 ubiquitin ligase CRL4 ${ }^{\text {DCAF1 } 1}$, which promotes the ubiquitylation of LATS1/2 to activate YAP. In merlin-deficient cells, YAP/TAZ accumulates in the nucleus and forms hybrid transcription factors with TEA domain (TEAD) family proteins to promote the transcription of pro-proliferative genes, including PTGS2 and miR-29. PTGS2 encodes cyclooxygenase-2 (COX-2) that catalyzes the conversion of arachidonic acid (AA) to prostaglandin E-2 (PGE-2), thus promoting PGE-2 mediated MAPK, ERK, PI3K pathway. By inducing miR-29, YAP can also inhibit the translation of phosphatase and tensin homolog (PTEN), a broadly downregulated tumor suppressor in vestibular schwannoma. 


\subsubsection{Nuclear Factor-Kappa B (NF-кB)}

$\mathrm{NF}-\kappa \mathrm{B}$ is a ubiquitous, evolutionary conserved transcription factor central to cell growth, apoptosis, inflammation and various malignant diseases (103). As a group of homo- and hetero-dimeric proteins composed of members of the Rel family, NF- $\kappa$ B complexes includes p65/RelA, RelB, c-Rel, p50/p105 (NF$\kappa \mathrm{B} 1$ ), and p52/p100 (NF- $\mathrm{BB} 2$ ) five subunits (104), and resides in the cytoplasm of non-stimulating cells in the form of complexes with inhibitor of $\kappa \mathrm{B}(\mathrm{I} \kappa \mathrm{B})$. The NF- $\kappa \mathrm{B}$ signaling pathway is activated by inflammatory cytokines or growth factors, and induces gene transcription of these factors in a feedback-loop way (Figure 3) (105-107).

Studies have shown that merlin negatively regulates $N F-\kappa B$ signaling, and the elevated NF- $\mathrm{KB}$ signal was considered as the hub of the interaction network of aberrant expressed molecules in VS pathobiology $(29,30,108)$. In the absence of merlin, overexpressed NIK and IKK $\alpha$ induced high NF- $\kappa \mathrm{B}$ dependent transcription (29), while merlin expression blocks NF- $\mathrm{KB}$ activation by the inhibition of p65, NIK, IKK $\alpha$, tumor necrosis factor- $\alpha$ (TNF- $\alpha$ )-induced I $\kappa B$ degradation, NF- $\kappa B-D N A$ binding and endogenous NF- $\kappa \mathrm{B}$ signaling (30). Besides, activated NF- $\kappa B$ is thought to be the mechanism by which elevated $\mathrm{p} 75^{\mathrm{NTR}}$ expression promotes cell survival in VS (109). Hyper NF- $\kappa \mathrm{B}$ activity in VS potentiated hepatocyte growth factor (HGF) to c-Met autocrine feed-forward loop to promote tumor cell proliferation (108), and increased the expression of factors that reported to be increased in VS or correlated with the prognosis or absolute tumor growth rate of VS, such as matrix metalloproteinase 2 (MMP-2), MMP-9 (40), MMP-14 (41), COX-2 (110), interleukin-1 (IL-1), IL-6, TNF- $\alpha$ (64) and signal transducers and activators of transcription 1 (STAT1) (111).

\subsubsection{Cyclooxygenase-2 (COX-2)}

COX-2 is an isozyme of the COX family, catalyzes the conversion of arachidonic acid to prostaglandins, including the biosynthesis of prostaglandin E-2 (PGE-2). In a healthy state, COX-2 is involved in maintaining cell homeostasis, while its response to homeostatic dysregulation might lead to the development of cancer (112). Studies have demonstrated that COX-2 is upregulated in various solid tumors and involved in cancer inflammation (113). COX-2 is released to the cancer microenvironment by type II macrophages, cancer-associated fibroblasts and tumor cells, and can suppress tumor cell apoptosis, enhance cell adhesion to promote tumor-induced angiogenesis and achieve an aggressive phenotype $(114,115)$.

COX-2 presented at high levels in majority (96.67\%) of VS tissue samples, and those VSs with higher COX-2 expression showed higher proliferation rate (31). Transcription of COX-2 is thought to be promoted by NF- $\kappa \mathrm{B}$. Aspirin modifies both NF- $\kappa \mathrm{B}$ signaling and COX-2 expression (116), and has been shown to

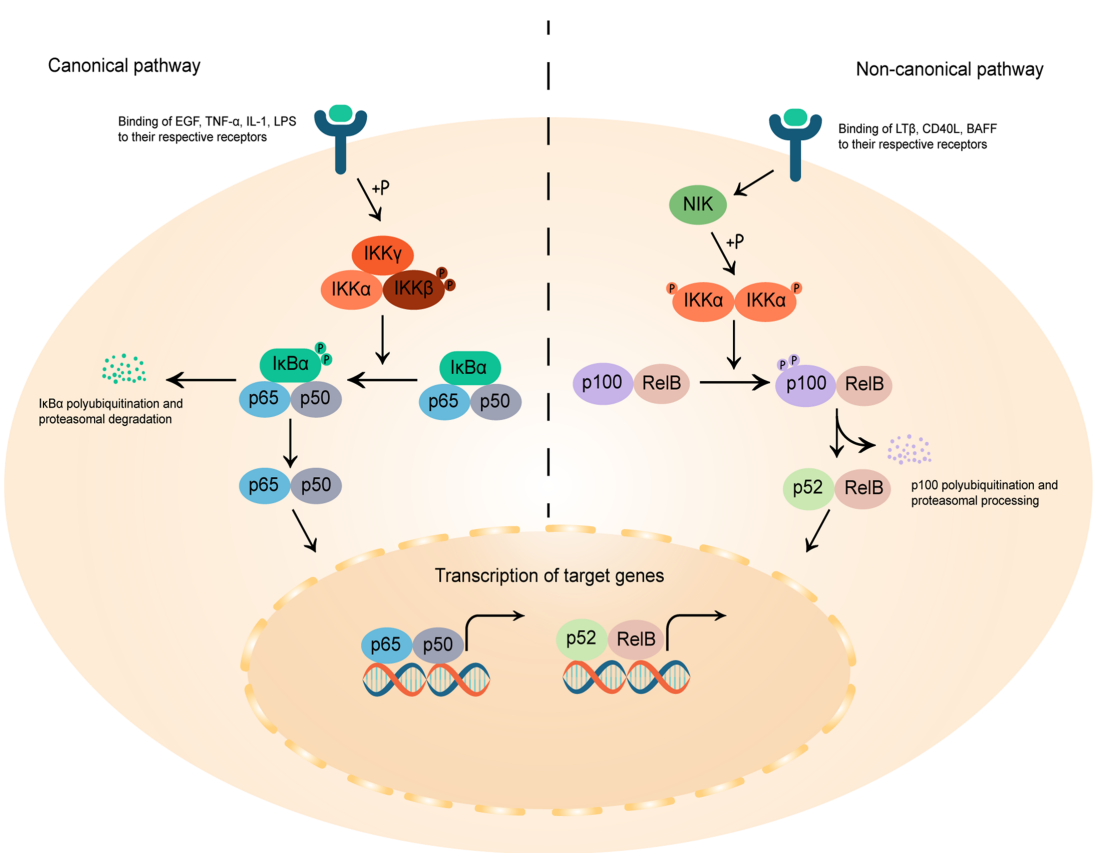

FIGURE 3 | Schematic diagram of the canonical and non-canonical NF- $\kappa B$ signaling pathway. In the canonical pathway, on the left, the binding of epidermal growth factor (EGF), tumor necrosis factor- $\alpha$ (TNF- $\alpha$ ), interleukin-1 (IL-1) and lipopolysaccharides (LPS) to their respective receptors lead to the phosphorylation of inhibitor of $\kappa \mathrm{B}(\mathrm{I} \mathrm{\kappa B})-\mathrm{kinase} \beta(\mathrm{IKK} \beta)$ in the IKK complex, which in turn phosphorylates $\mid \kappa B \alpha$, culminating in its polyubiquitination and proteasomal degradation. The free $\mathrm{NF}-\kappa \mathrm{B}$ homo- or heterodimers, in this case p65/p50, then translocate into the nucleus to bind to $\kappa \mathrm{B}$ motif and promote target gene transcription. The non-canonical pathway, on the right, is activated by the binding of lymphtoxin $\beta$ (LT $\beta$ ), CD40 ligand (CD4OL), and B-cell activating factor (BAFF) to their respective receptors, causing IKK $\alpha$ dimers phosphorylation by the NF-KB-inducing kinase (NIK). Phosphorylation of p100 by activated IKK $\alpha$ initiates proteasomal processing of $\mathrm{p} 100 \mathrm{~N}-$ terminal to form p52. The p52/RelB heterodimers can then undergoes nuclear translocation and modulates the gene transcription of pro-inflammatory cytokines in a feedback-loop way. 
have therapeutic effects in several tumors with high COX-2 levels $(117,118)$. Although some studies have shown that aspirin may halt VS growth $(119,120)$, the latest meta-analysis disproved this viewpoint (121).

\subsubsection{Macrophages}

Tumor associated macrophages (TAMs) can be broadly classified into two categories, both of which are differentiated from monocytes in response to stimulus signals (122). The first type is M1-type inflammatory macrophages, also known as classically activated macrophages. M1-type macrophages are critically important in host defense and killing of tumor cells by the production of pro-inflammatory cytokines such as interferon- $\gamma$ (IFN- $\gamma$ ), TNF- $\alpha$ and IL-18, which have potent microbiomekilling properties and hence are considered as 'good' macrophages (123). In order to avoid collateral damage to healthy cells/tissues by M1-type macrophages, M2-type macrophages, or alternatively activated macrophages, usually presented at the later stage of inflammatory response to suppressing destructive immunity, promoting wound repair and fibrosis. The effects of M2-type macrophages are manifested in the tumor microenvironment as inhibiting antitumor immunity, promoting tumor matrix remodeling and inducing angiogenesis (123). Collective data have shown that the high densities of M2-type macrophages in the tumor microenvironment are associated with the secretion of VEGF and MMP-9 (124), and worse prognosis in numerous cancer types $(125,126)$.

In a previous study, it was demonstrated that macrophages, rather than tumor cells, accounted for the majority of proliferating cells in the growing sporadic VS (32). Using Iba-1 as a pan-macrophage marker, the study of 24 sporadic VSs and $20 \mathrm{NF} 2$-related VSs showed that the microvessel surface area was positively correlated with TAM density, and that Iba-1+ macrophages contributed significantly to VEGF production (127). This supports the idea that targeting macrophages along with vascular supply should be viewed as promising therapeutic options in both VS groups.

de Vries et al. determined the role of M2-type macrophages in promoting angiogenesis and volumetric tumor growth in sporadic VS tissue sections. They compared the expression of CD163, a specific marker for M2-type macrophages, in 10 rapidly growing VSs and 10 slow-growing VSs, and found that CD163 expression was significantly higher in fast-growing VS, and tumors with higher CD163 expression had more microvessels (as assessed by CD31). Consistent with these findings, the levels of macrophage colony-stimulating factor (M-CSF), an important cytokine that stimulates macrophage polarization into an M2-type macrophage, and its synergistic cytokine interleukin-34 (IL-34), are increased in fast-growing VS, suggesting their potential function as promoters of tumor progression (33). Recently, Bi et al. demonstrated variable expression of immune regulatory markers as well as immune infiltrates in VS (128). They found both tumor volume and volumetric growth were positively correlated with CD163 expression, and the relationship between PD-L1 and growth strengthened with increasing CD163 infiltration, suggesting a prominent role of immunotherapy in VS treatment (128).

\subsubsection{Neutrophil-to-Lymphocyte Ratio (NLR)}

As a representative index of systemic inflammation, preoperative peripheral blood NLR is related to the pathological characteristics of many tumors (129). The pretreatment NLR is calculated according to the absolute neutrophil count (ANC) and the absolute lymphocyte count (ALC) of routine blood tests obtained prior to any intervention. A high NLR indicated greater systemic inflammation and elevated circulating concentrations of pro-inflammatory and angiogenic cytokines, which can enhance tumor progression, immunosuppression and peritumoral stroma formation, and therefore is considered as a promising negative prognostic biomarker in solid tumors (130).

The utility of NLR has been pointed for predicting oncological growth in patients with VS. Kontorinis et al. found a significant difference of NLR between 79 growing VSs and 82 non-growing VSs, with high NLR was observed predominantly in the growing VS group (34). However, there is no such discrepancy between regressing VS and growing VS (131). A probable speculation is that NLR-associated inflammation functions not only in the pathomechanism of tumor growth, but also in the decrease of tumor size. Currently, the critical limitation needs to be obviated for NLR's clinical application and further investigation is that there is no consensus on the cutoff value of NLR (34).

\section{3 miRNAs}

miRNAs are small non-coding RNAs that responsible for the post-transcriptional regulation of genes by partially or perfectly complementary to the target mRNAs, leading to protein synthesis abortion or transcription inhibition (132). miRNAs play an important role in tumor initiation and development, and are potential targets for therapeutic interventions in diverse cancers.

Several differentially expressed miRNAs have been identified in VS tissues $(133,134)$. Using principal component analysis, affected gene ontology analysis, and analysis of miRNA expression fold changes, Sass et al. determined the relationship between rapid tumor growth and upregulation of miR-29abc, miR-19, miR-340-5p, miR-21, miR-221 and downregulation of miR-744 and let-7b (35). miR-29 fulfills controversial function in tumor progression and invasion in different tumors (135-137), and was reported to be upregulated in previous VS studies (134). Concordant with this research, Cioffi et al. demonstrated that miR-21 was over-expressed in VS compared with normal vestibular nerve tissue (36). Yang et al. found that downregulation of $\mathrm{miR}-21$ by ailanthone reduced the proliferative potential of VS cells and induced apoptosis and autophagy (89). Other deregulated miRNAs also serve as modulators of tumor-related signaling pathways, such as miR340 in Ras/Raf/MAPK (138) and let-7b in SOCS1/STAT (139). Notably, the contributions of miR-19, miR-21 and miR-221 to tumor growth are all related to their down-regulation of tumor suppressor PTEN $(36,136,140)$, suggesting the role of PTEN and 
its downstream $\mathrm{PI} 3 \mathrm{~K} / \mathrm{Akt} / \mathrm{mTOR}$ signaling pathway in VS cancerigenic process.

\subsection{Proteins in Tumor Tissue}

CD105, better known as endoglin, is a homodimeric transmembrane glycoprotein that highly expressed on activated angiogenic endothelial cells (141). Used as a marker of MVD, CD105 has proven itself as a potent prognostic indicator and a potential target for antiangiogenic therapy and chimeric antigen receptor-based T-cell (CAR-T) immunotherapy in several tumors (142-144). Calculated by immunohistochemically assessed CD105 expression, Gino et al. correlated the vessel cross-sectional area (VA) and vessel density (VD) with tumor dimensions and tumor growth rate in both NF2-associated VS and sporadic VS, and found a positive correlation between VD and tumor growth rate in NF2-VS, and VA and VD with tumor size in sporadic VS (37). Considering the great achievements of anti-angiogenesis therapy in VS and the specificity of CD105 to indicate the vascular front where sprouting takes place, it seems reasonable to use circulating CD105 to monitor tumor growth and to treat VS with anti-endoglin antibodies.

With several over-expressed neurotrophic factors in VS drawn attention as putative key mediators of tumor growth, Kramer et al. explored the relationship between gene expression profiles of neurotrophic factors and proliferation-associated Ki67 labelling index, and observed significantly elevated brain derived neurotrophic factor (BDNF) expression that correlated with mitotic activity in VS (38).BDNF plays a pivotal role in myelination processing and supports the survival and synaptic integrity of the auditory nerve (145). This mitosis-promoting neurotrophic factor, together with the previously mentioned bFGF, which has the dual effects of hearing protection and growth stimulation of VS cells $(16,75)$, may partially explain the seemingly paradoxical phenomenon that VS patients with tumor growth do not necessarily experience hearing loss.

MMPs comprise a large family of zinc- and calciumdependent proteolytic enzymes. Apart from their essential role in promoting cell differentiation and the reconstruction of the extracellular matrix in a regenerative milieu, MMPs play a fundamental role in tumor progression, invasion, and angiogenesis (146). Expression characteristics of several MMPs family members in VS have been explored. MMP-2 and its endogenous inhibitors tissue inhibitors of metalloproteinase (TIMP)-1 were found interstitially in sporadic solid VS, while the majority of MMP-9 was localized in tumor cells, and its concentration in tumor sample homogenates was positively correlated with the absolute tumor growth rate (40). Consistent with previous studies showing that the proteolytic activity of MMPs might degrade collagen, fibronectin, laminin and contribute to cyst formation and expansion, the expression of MMP-2 and MMP-9 were upregulated in cystic VS samples compared with solid VS (147). In cystic VS tissues, MMP-2 was localized to tumor cells on the cyst cavity inner surface and its levels were higher in the cystic fluid than in other samples (148).

Histologically, VS can be classified into two tissue types, where Antoni type A has a compact structure with interwoven bundles of long bipolar spindle cells and Antoni type B characterized by a loose texture and small, uniform satellite cells. It is known that cystic VS consist of a large mass of Antoni type B area, where the expression of MMP-14 was significantly higher than that in Antoni type A (39). The abundance and proteolytic activity of MMP-14 in VS patients was correlated with the degree of SNHL and surgical outcomes (41). Besides, MMP-2, MMP-9 and MMP14 are all principal proteins of the MMPs family in the vasculature, implying degeneration of tumor tissues by MMPs and the accompanying increased tumor vessel permeability and adhesion to the facial nerve are critical in VS tumorigenesis, cyst formation and preoperative hearing impairment.

As a membrane-anchored protein of the A-Disintegrin and Metalloproteinase (ADAM) protein family, the overexpression of ADAM9 in solid tumors has been correlated with aggressive tumor phenotypes and unfavorable clinical prognosis (149). ADAM9 may implicated in tumor progression and invasion either via non-proteolytic mechanisms that include interactions between tumor cells and endothelial or peritumoral stromal cells (150), or proteolytic mechanisms that involve an enzymatic modification called "shedding" or processing of cell-surface proteins (151). The value of ADAM9 inhibition in reducing migration and invasion of different solid tumors has been established (152, 153). The earliest expression assessment of ADAM9 in VS by Breun et al. found an 8.8-fold higher ADAM9 mRNA level in VS compared with in healthy peripheral nerves, and a strong correlation between ADAM9 mRNA expression and the degree of functional impairment (42). Further, in VS primary cell cultures, ADAM9 knock down caused a $58 \%$ reduction in cell numbers, which might be a hint that ADAM9 plays a role in inducing VS progression (43).

\subsection{Components in Cerebrospinal Fluid}

VSs usually originate from Schwann cells of the cisternal portion of nerve rootlets exposed to CSF and may alter CSF composition by secreting proteins or altering CSF metabolism (154). CSFbased liquid biopsy approaches have been used to characterize protein expression during the pathogenesis of several brain tumors $(155,156)$, and differential components analyses of CSF are also expected to yielded diagnostic and therapeutic targets in VS.

Two studies have been done on CSF composition to identify biomarkers that predict VS growth. Ariyannur et al. found the levels of hyaluronan (HA) were 17-fold higher in NF2-related VS cases compared to the controls, and the rate of HA synthesis and secretion by primary schwannoma cells was commensurate with their proliferation rate (44). HA is a cell-surrounding mucopolysaccharide that binds to the Schwann cell surface CD44 receptor to trigger an uninterrupted cell proliferation cascade. Deranged HA-CD44 interaction has been identified as one of the central causative factors for schwannoma and a tumor suppressor target of merlin (157). Schwannoma cells increase their selfreproductive potential by secreting $\mathrm{HA}$ under the innate condition, suggesting that elevated HA in the CSF of patients with NF2-VS may be used as an indicator of tumor growth.

By characterizing the CSF proteome among VS patients with different grades, Huang et al. found that ATP-binding cassette subfamily A member 3 (ABCA3), secretogranin-1 (SCG1), 
Krueppel-like factor 11 (KLF11), voltage-dependent calcium channel subunit alpha-2/delta-1 (CA2D1), brain acid soluble protein 1 (BASP1), and peroxiredoxin-2 (PRDX2) in CSF were associated with VS growth (45). It is notable that some of them did not simply increase or decrease as the tumor grows, but reached their maximum or minimum values at certain phases, suggesting that volumetric growth of VS may be driven by different signaling pathways at different tumor stages.

\section{DISCUSSION}

VS is a benign but potentially devastating tumor whose aggressively growth can be associated with significant morbidity including deafness and facial neuropathy. Usually, treatment of VS relies on surgery, radiation and regular follow-up. Better knowledge of the pathogenesis of VS has led to several targeted therapies with the effect of reducing tumor volume or restoring patients' hearing, of which bevacizumab has achieved the most promising results (68).

The majority of VSs may not enlarge after initial diagnosis, with an average annual growth rate of $1.11 \mathrm{~mm}$ (9). In order to preserve hearing function and enhance the quality of life, a substantial proportion of newly diagnosed patients will choose wait-and-scan policy, who were put at the risk of sudden tumor growth due to extremely variable growth patterns of VS. Hence, it would be helpful to identify predictive factors for VS growth at time of diagnosis. Several epidemiological, clinical, and radiological characteristics were thought to be related to the increased risk of subsequent tumor growth, such as patients' age, tumor location, hearing loss, and grow at first follow-up $(9,12-14)$. But there were some inconsistencies among reports of predicting growth-related factors (9), making the accuracy of this approach debatable.

From the perspective of VS growth mechanisms, numerous achievements had been obtained in exploring the relationship between tumor growth and biomarkers. The exact mechanism of VS onset and progression has remained elusive, with only a broad association with genetic and epigenetic aberrations of merlin, inflammation factors, proteolytic enzymes and nutrient supply pathways. Notably, there are mutual interactions between abnormally expressed molecules in VS biology. Merlin, whose conformational changes are regulated by RTKs and integrin signals, is also an inhibitor of the pro-inflammatory transcription factor NF- $\mathrm{KB}$ (30). On the other hand, high numbers of tumor infiltrating leukocytes in VS tissues can enhance cell survival, promote tumor growth and degenerative changes through the production of growth factors, cytokines, and MMPs (33, 128, 158). These evidences indicate that the progression of VS appears to be the result of interactions of these dysregulated pathways, drugs that target multiple signaling pathways simultaneously merit further investigation.

Despite the many recent advances in the identification of growth-related biomarkers, their translational researches have encountered several problems. First, current available VS animal models have some limitations. The commonly utilized animal models for the study of VS including patient-derived xenograft mice model (159), merlin-deficient Schwann cell or SC4 cells mouse model $(160,161)$. Nevertheless, merlin-deficient Schwann cells may not accurately reproduce VS (162), and it takes more than 2 weeks for the construction of mouse model. Recently proposed zebrafish xenograft model with shorter period of model establishment (163), as well as the application of 3D in vitro cell culture system (164) and ex vivo organ cultures (165) that fully mirror the growth patterns of VS, promise to further elucidate the role of these biomolecules in the pathogenesis of VS. Second, clinical validation of these hypotheses should take tumor diameter and clinical course into consideration. Current studies demonstrate non-linear changes of protein expression as VS size increases (45), suggesting that tumor progression at different grades might be stimulated by different signaling pathways and can therefore be predicted by different biomarkers. Along similar lines, different stages of the natural course of VS might be driven by different mechanisms either. During the enlarge of VS, accelerated growth, regression, or quiescence of the tumor can occur at any stage (2). Classifying patients according to the growth characteristics of VS and analyzing biomarker levels in different groups would shed light on which pathway induces VS initiation and which involves in VS shrinkage or growth cessation. Third, research is urgently needed to address how to obtain tissue expression data in a non-traumatic way. MRI texture analysis have been previously associated with VEGF expression in head and neck squamous cell carcinoma (166), and might also reflected VEGF levels in VS. A more precise non-invasive in vivo marker expression evaluation technique is targeted molecular imaging [MRI, computed tomography (CT), positron emission computed tomography/single-photon emission computed tomography (PET/SPECT) and fluorescence] (161, 167-169). Recently, Morrison et al. injected the covalently linked compounds formed by anti-VEGFR2 or anti-Her2/Neu monoclonal antibodies and near-infrared probe into Schwann cell xenograft models in mice, and observed strong correlations between day 1 tumor fluorescence and eventual maximum tumor volume (170). Apart from advanced imaging techniques, the circulating biomarkers level could also serve as convenient and reliable indicators for the prediction of subsequent tumor growth $(37,44)$.

We highlight some of the known and novel indicators with potential to predict VS growth enlightened therapeutic targets of VS and are critical for clinicians in stratifying patient's risk preoperatively, formulating individualized therapeutic tactics, and guiding clinical trial enrollment.

\section{AUTHOR CONTRIBUTIONS}

$\mathrm{YZ}$ and JL wrote the first draft of the paper. JR and XH revised the draft. PZ and BW provided approval for publication of this review. All authors contributed to the article and approved the submitted version.

\section{FUNDING}

This study was sponsored by Shanghai Science and Technology Committee Youth Sailing Program (19YF1405700), Clinical 
Research Plan of Shenkang Hospital Development Center (SHDC2020CR1049B), Chinese Academy of Medical Sciences Innovation Fund for Medical Sciences (2019-I2M-5008), National Natural Science Foundation of China (NSFC81872938, 82003864).

\section{REFERENCES}

1. Jia H, Lahlou G, Wu H, Sterkers O, Kalamarides M. Management of Neurofibromatosis Type 2 Associated Vestibular Schwannomas. Curr Otorhinolaryngol Rep (2021) 9(2):170-6. doi: 10.1007/s40136-021-00341-x

2. Tan D, Killeen DE, Kutz JW. The Natural History of Vestibular Schwannoma and When to Intervene. Curr Otorhinolaryngol Rep (2021) 9(2):134-8. doi: 10.1007/s40136-021-00337-7

3. Huang X, Xu J, Xu M, Zhou L-F, Zhang R, Lang L, et al. Clinical Features of Intracranial Vestibular Schwannomas. Oncol Lett (2013) 5(1):57-62. doi: 10.3892/ol.2012.1011

4. Halliday J, Rutherford SA, McCabe MG, Evans DG. An Update on the Diagnosis and Treatment of Vestibular Schwannoma. Expert Rev Neurother (2018) 18(1):29-39. doi: 10.1080/14737175.2018.1399795

5. Pandrangi VC, Han AY, Alonso JE, Peng KA, St John MA. An Update on Epidemiology and Management Trends of Vestibular Schwannomas. Otol Neurotol (2020) 41(3):411-7. doi: 10.1097/mao.0000000000002542

6. Pritchard C, Clapham L, Davis A, Lang DA, Neil-Dwyer G. Psycho-SocioEconomic Outcomes in Acoustic Neuroma Patients and Their Carers Related to Tumour Size. Clin Otolaryngol (2004) 29(4):324-30. doi: 10.1111/j.1365-2273.2004.00822.x

7. Hasegawa T, Kida Y, Kato T, Iizuka H, Kuramitsu S, Yamamoto T. LongTerm Safety and Efficacy of Stereotactic Radiosurgery for Vestibular Schwannomas: Evaluation of 440 Patients More Than 10 Years After Treatment With Gamma Knife Surgery Clinical Article. J Neurosurg (2013) 118(3):557-65. doi: 10.3171/2012.10.Jns12523

8. Suryanarayanan R, Ramsden RT, Saeed SR, Aggarwal R, King AT, Rutherford SA, et al. Vestibular Schwannoma: Role of Conservative Management. J Laryngol Otol (2010) 124(3):251-7. doi: 10.1017/ s0022215109992362

9. Paldor I, Chen AS, Kaye AH. Growth Rate of Vestibular Schwannoma. J Clin Neurosci (2016) 32:1-8. doi: 10.1016/j.jocn.2016.05.003

10. Martin TPC, Tzifa K, Kowalski C, Holder RL, Walsh R, Irving RM. Conservative Versus Primary Surgical Treatment of Acoustic Neuromas: A Comparison of Rates of Facial Nerve and Hearing Preservation. Clin Otolaryngol (2008) 33(3):228-35. doi: 10.1111/j.1749-4486.2008.01715.x

11. Goshtasbi K, Abouzari M, Moshtaghi O, Sahyouni R, Sajjadi A, Lin HW, et al. The Changing Landscape of Vestibular Schwannoma Diagnosis and Management: A Cross-Sectional Study. Laryngoscope (2020) 130(2):482-6. doi: 10.1002/lary.27950

12. Kim JS, Cho Y-S. Growth of Vestibular Schwannoma: Long-Term FollowUp Study Using Survival Analysis. Acta Neurochir (2021)163(8):2237-45. doi: 10.1007/s00701-021-04870-8. in press.

13. Roehm PC, Gantz BJ. Management of Acoustic Neuromas in Patients 65 Years or Older. Otol Neurotol (2007) 28(5):708-14. doi: 10.1097/ 01.mao.0000281805.44197.ec

14. Lee JD, Park MK, Kim JS, Cho Y-S. The Factors Associated With Tumor Stability Observed With Conservative Management of Intracanalicular Vestibular Schwannoma. Otol Neurotol (2014) 35(5):918-21. doi: 10.1097/ mao.0000000000000338

15. Higuchi Y, Ikegami S, Horiguchi K, Aoyagi K, Nagano O, Serizawa T, et al. Predicting Potential of Rapid Tumor Growth in Small to Medium Vestibular Schwannomas on the Basis of Sway Assessed Using Posturography. World Neurosurg (2021) 148:E406-14. doi: 10.1016/j.wneu.2020.12.175

16. Koutsimpelas D, Stripf T, Heinrich UR, Mann WJ, Brieger J. Expression of Vascular Endothelial Growth Factor and Basic Fibroblast Growth Factor in Sporadic Vestibular Schwannornas Correlates to Growth Characteristics. Otol Neurotol (2007) 28(8):1094-9. doi: 10.1097/MAO.0b013e31814b2787

17. Sabha N, Au K, Agnihotri S, Singh S, Mangat R, Guha A, et al. Investigation of the In Vitro Therapeutic Efficacy of Nilotinib in Immortalized Human

\section{ACKNOWLEDGMENTS}

The authors wish to acknowledge all staff of the Pharmacy Department and Neurosurgery Department of Huashan Hospital West Campus.

NF2-Null Vestibular Schwannoma Cells. PloS One (2012) 7(6):10 doi: 10.1371/journal.pone.0039412

18. Mukherjee J, Kamnasaran D, Balasubramaniam A, Radovanovic I, Zadeh G, Kiehl TR, et al. Human Schwannomas Express Activated Platelet-Derived Growth Factor Receptors and C-Kit and Are Growth Inhibited by Gleevec (Imatinib Mesylate). Cancer Res (2009) 69(12):5099-107. doi: 10.1158/00085472.can-08-4475

19. Blair KJ, Kiang A, Wang-Rodriguez J, Yu MA, Doherty JK, Ongkeko WM EGF and bFGF Promote Invasion That Is Modulated by PI3/Akt Kinase and Erk in Vestibular Schwannoma. Otol Neurotol (2011) 32(2):308-14. doi: 10.1097/MAO.0b013e318206fc3d

20. Doherty JK, Ongkeko W, Crawley B, Andalibi A, Ryan AF. ErbB and Nrg: Potential Molecular Targets for Vestibular Schwannoma Pharmacotherapy. Otol Neurotol (2008) 29(1):50-7. doi: 10.1097/mao.0b013e31815d4429

21. Lim JY, Kim H, Jeun SS, Kang SG, Lee KJ. Merlin Inhibits Growth HormoneRegulated Raf-ERKs Pathways by Binding to Grb2 Protein. Biochem Biophys Res Commun (2006) 340(4):1151-7. doi: 10.1016/j.bbrc.2005.12.122

22. Kissil JL, Wilker EW, Johnson KC, Eckman MS, Yaffe MB, Jacks T. Merlin, the Product of the Nf2 Tumor Suppressor Gene, the P21-Activated Is an Inhibitor of Kinase, Pak1. Mol Cell (2003) 12(4):841-9. doi: 10.1016/s10972765(03)00382-4

23. Yi C, Troutman S, Fera D, Stemmer-Rachamimov A, Avila JL, Christian N et al. A Tight Junction-Associated Merlin-Angiomotin Complex Mediates Merlin's Regulation of Mitogenic Signaling and Tumor Suppressive Functions. Cancer Cell (2011) 19(4):527-40. doi: 10.1016/j.ccr.2011.02.017

24. Jin HC, Sperka T, Herrlich P, Morrison H. Tumorigenic Transformation by CPI-17 Through Inhibition of a Merlin Phosphatase. Nature (2006) 442 (7102):576-9. doi: 10.1038/nature04856

25. Hagel C, Dornblut C, Schulz A, Wiehl U, Friedrich RE, Huckhagel T, et al. The Putative Oncogene CPI-17 Is Up-Regulated in Schwannoma. Neuropathol Appl Neurobiol (2016) 42(7):664-8. doi: 10.1111/nan.12330

26. Xu JH, Zhang Y, Shi YX, Yin DM, Dai PD, Zhao WD, et al. CPI-17 Overexpression and Its Correlation With the NF2 Mutation Spectrum in Sporadic Vestibular Schwannomas. Otol Neurotol (2020) 41(1):E94-102. doi: $10.1097 / \mathrm{ma} 0.0000000000002430$

27. Zhao F, Yang ZJ, Chen Y, Zhou QY, Zhang J, Liu J, et al. Deregulation of the Hippo Pathway Promotes Tumor Cell Proliferation Through YAP Activity in Human Sporadic Vestibular Schwannoma. World Neurosurg (2018) 117: E269-79. doi: 10.1016/j.wneu.2018.06.010

28. Li W, Giancotti FG. Merlin's Tumor Suppression Linked to Inhibition of the E3 Ubiquitin Ligase CRL4 (Dcaf1). Cell Cycle (Georgetown Tex) (2010) 9 (22):4433-6. doi: 10.4161/cc.9.22.13838

29. Dilwali S, Briet MC, Kao SY, Fujita T, Landegger LD, Platt MP, et al. Preclinical Validation of Anti-Nuclear Factor-Kappa B Therapy to Inhibit Human Vestibular Schwannoma Growth. Mol Oncol (2015) 9(7):1359-70. doi: 10.1016/j.molonc.2015.03.009

30. Kim JY, Kim H, Jeun SS, Rha SJ, Kim YH, Ko YJ, et al. Inhibition of NFKappa B Activation by Merlin. Biochem Biophys Res Commun (2002) 296 (5):1295-302. doi: 10.1016/s0006-291x(02)02077-6

31. Hong B, Krusche CA, Schwabe K, Friedrich S, Klein R, Krauss JK, et al Cyclooxygenase-2 Supports Tumor Proliferation in Vestibular Schwannomas. Neurosurgery (2011) 68(4):1112-7. doi: 10.1227/NEU.0b013e318208f5c7

32. Lewis D, Roncaroli F, Agushi E, Mosses D, Williams R, Li KL, et al. Inflammation and Vascular Permeability Correlate With Growth in Sporadic Vestibular Schwannoma. Neuro Oncol (2019) 21(3):314-25. doi: 10.1093/neuonc/noy177

33. de Vries WM, Briaire-de Bruijn IH, van Benthem PPG, van der Mey AGL, Hogendoorn PCW. M-CSF and IL-34 Expression as Indicators for Growth in Sporadic Vestibular Schwannoma. Virchows Arch (2019) 474(3):375-81. doi: 10.1007/s00428-018-2503-1 
34. Kontorinis G, Crowther JA, Iliodromiti S, Taylor WAS, Locke R. Neutrophil to Lymphocyte Ratio as a Predictive Marker of Vestibular Schwannoma Growth. Otol Neurotol (2016) 37(5):580-5. doi: 10.1097/mao.0000000000001026

35. Sass HCR, Hansen M, Borup R, Nielsen FC, Caye-Thomasen P. Tumor miRNA Expression Profile Is Related to Vestibular Schwannoma Growth Rate. Acta Neurochir (2020) 162(5):1187-95. doi: 10.1007/s00701-020-04238-4

36. Cioff JA, Yue WY, Mendolia-Loffredo S, Hansen KR, Wackym PA, Hansen MR. MicroRNA-21 Overexpression Contributes to Vestibular Schwannoma Cell Proliferation and Survival. Otol Neurotol (2010) 31(9):1455-62. doi: 10.1097/MAO.0b013e3181f20655

37. Marioni G, Nicol L, Cazzador D, Pavone C, D'Avella D, Martini A, et al. Endoglin (CD105) Expression in Neurofibromatosis Type 2 Vestibular Schwannoma. Head Neck J Sci Spec (2019) 41(10):3612-7. doi: 10.1002/ hed.25881

38. Kramer F, Stoever T, Warnecke A, Diensthuber M, Lenarz T, Wissel K. BDNF mRNA Expression Is Significantly Upregulated in Vestibular Schwannomas and Correlates With Proliferative Activity. J Neurooncol (2010) 98(1):31-9. doi: 10.1007/s11060-009-0063-6

39. Xia L, Yang S, Wang CD, Yu EX, Zhang HL, Zhang Y, et al. Immunohistochemical Profiles of Matrix Metalloproteinases and Vascular Endothelial Growth Factor Overexpression in the Antoni B Area of Vestibular Schwannomas. World Neurosurg (2020) 144:E72-9. doi: 10.1016/ j.wneu.2020.07.208

40. Moller MN, Werther K, Nalla A, Stangerup SE, Thomsen J, Bog-Hansen TC, et al. Angiogenesis in Vestibular Schwannomas: Expression of Extracellular Matrix Factors MMP-2, MMP-9, and TIMP-1. Laryngoscope (2010) 120 (4):657-62. doi: 10.1002/lary.20834

41. Ren Y, Hyakusoku H, Sagers JE, Landegger LD, Welling DB, Stankovic KM. MMP-14 (MT1-MMP) Is a Biomarker of Surgical Outcome and a Potential Mediator of Hearing Loss in Patients With Vestibular Schwannomas. Front Cell Neurosci (2020) 14:191. doi: 10.3389/fncel.2020.00191

42. Breun M, Schwerdtfeger A, Martellotta DD, Kessler AF, Monoranu CM, Matthies C, et al. ADAM9: A Novel Player in Vestibular Schwannoma Pathogenesis. Oncol Lett (2020) 19(3):1856-64. doi: 10.3892/ol.2020.11299

43. Nattmann A, Breun M, Monoranu CM, Matthies C, Ernestus RI, Lohr M, et al. Analysis of ADAM9 Regulation and Function in Vestibular Schwannoma Primary Cells. BMC Res Notes (2020) 13(1):528. doi: 10.1186/s13104-020-05378-7

44. Ariyannur PS, Vikkath N, Pillai AB. Cerebrospinal Fluid Hyaluronan and Neurofibromatosis Type 2. Cancer Microenviron (2018) 11(2-3):125-33. doi: 10.1007/s12307-018-0216-2

45. Huang X, Xu J, Shen YW, Zhang L, Xu M, Chen MY, et al. Protein Profiling of Cerebrospinal Fluid From Patients Undergoing Vestibular Schwannoma Surgery and Clinical Significance. BioMed Pharmacother (2019) 116:108985. doi: 10.1016/j.biopha.2019.108985

46. Asthagiri AR, Parry DM, Butman JA, Kim HJ, Tsilou ET, Zhuang Z, et al. Neurofibromatosis Type 2. Lancet (2009) 373(9679):1974-86. doi: 10.1016/ s0140-6736(09)60259-2

47. Lee JD, Kwon TJ, Kim UK, Lee WS. Genetic and Epigenetic Alterations of the NF2 Gene in Sporadic Vestibular Schwannomas. PloS One (2012) 7(1):5. doi: 10.1371/journal.pone. 0030418

48. Bretscher A, Edwards K, Fehon RG. ERM Proteins and Merlin: Integrators at the Cell Cortex. Nat Rev Mol Cell Biol (2002) 3(8):586-99. doi: 10.1038/ nrm882

49. Zoch A, Mayerl S, Schulz A, Greither T, Frappart L, Rubsam J, et al. Merlin Isoforms 1 and 2 Both Act as Tumour Suppressors and Are Required for Optimal Sperm Maturation. PloS One (2015) 10(8):25. doi: 10.1371/ journal.pone. 0129151

50. Maccollin M, Ramesh V, Jacoby LB, Louis DN, Rubio MP, Pulaski K, et al. Mutational Analysis of Patients With Neurofibromatosis-2. Am J Hum Genet (1994) 55(2):314-20.

51. Goutagny S, Raymond E, Esposito-Farese M, Trunet S, Mawrin C, Bernardeschi D, et al. Phase II Study of Mtorc1 Inhibition by Everolimus in Neurofibromatosis Type 2 Patients With Growing Vestibular Schwannomas. J Neurooncol (2015) 122(2):313-20. doi: 10.1007/s11060-014-1710-0

52. Petrilli AM, Fuse MA, Donnan MS, Bott M, Sparrow NA, Tondera D, et al. A Chemical Biology Approach Identified PI3K as a Potential Therapeutic Target for Neurofibromatosis Type 2. Am J Transl Res (2014) 6(5):471-93.
53. Kaempchen K, Mielke K, Utermark T, Langmesser S, Hanemann CO. Upregulation of the Rac1/JNK Signaling Pathway in Primary Human Schwannoma Cells. Hum Mol Genet (2003) 12(11):1211-21. doi: 10.1093/ $\mathrm{hmg} / \mathrm{ddg} 146$

54. Li W, Cooper J, Zhou L, Yang C, Erdjument-Bromage H, Zagzag D, et al. Merlin/NF2 Loss-Driven Tumorigenesis Linked to CRL4(DCAF1)Mediated Inhibition of the Hippo Pathway Kinases Lats1 and 2 in the Nucleus. Cancer Cell (2014) 26(1):48-60. doi: 10.1016/j.ccr.2014.05.001

55. Mandati V, Del Maestro L, Dingli F, Lombard B, Loew D, Molinie N, et al. Phosphorylation of Merlin by Aurora A Kinase Appears Necessary for Mitotic Progression. J Biol Chem (2019) 294(35):12992-3005. doi: 10.1074/ jbc.RA118.006937

56. McClatchey AI, Fehon RG. Merlin and the ERM Proteins - Regulators of Receptor Distribution and Signaling at the Cell Cortex. Trends Cell Biol (2009) 19(5):198-206. doi: 10.1016/j.tcb.2009.02.006

57. Lallemand D, Saint-Amaux AL, Giovannini M. Tumor-Suppression Functions of Merlin Are Independent of Its Role as an Organizer of the Actin Cytoskeleton in Schwann Cells. J Cell Sci (2009) 122(22):4141-9. doi: $10.1242 /$ jcs. 045914

58. Sher I, Hanemann CO, Karplus PA, Bretscher A. The Tumor Suppressor Merlin Controls Growth in Its Open State, and Phosphorylation Converts It to a Less-Active More-Closed State. Dev Cell (2012) 22(4):703-5. doi: 10.1016/j.devcel.2012.03.008

59. Xing WC, Li M, Zhang FY, Ma X, Long JF, Zhou H. The Conformation Change and Tumor Suppressor Role of Merlin Are Both Independent of Serine 518 Phosphorylation. Biochem Biophys Res Commun (2017) 493 (1):46-51. doi: 10.1016/j.bbrc.2017.09.077

60. Shaw RJ, Paez JG, Curto M, Yaktine A, Pruitt WM, Saotome I, et al. The Nf2 Tumor Suppressor, Merlin, Functions in Rac-Dependent Signaling. Dev Cell (2001) 1(1):63-72. doi: 10.1016/s1534-5807(01)00009-0

61. Ye KQ. Phosphorylation of Merlin Regulates Its Stability and Tumor Suppressive Activity. Cell Adhes Migr (2007) 1(4):196-8. doi: 10.4161/ cam.1.4.5192

62. Wickremesekera A, Hovens CM, Kaye AH. Expression of ErbB-1 and 2 in Vestibular Schwannomas. J Clin Neurosci (2007) 14(12):1199-206. doi: 10.1016/j.jocn.2007.05.009

63. Altuna X, Lopez JP, Yu MA, Arandazi MJ, Harris JP, Wang-Rodriguez J, et al. Potential Role of Imatinib Mesylate (Gleevec, STI-571) in the Treatment of Vestibular Schwannoma. Otol Neurotol (2011) 32(1):163-70. doi: 10.1097/MAO.0b013e3182009665

64. Taurone S, Bianchi E, Attanasio G, Di Gioia C, Ierino R, Carubbi C, et al. Immunohistochemical Profile of Cytokines and Growth Factors Expressed in Vestibular Schwannoma and in Normal Vestibular Nerve Tissue. Mol Med Rep (2015) 12(1):737-45. doi: 10.3892/mmr.2015.3415

65. Ebrahem Q, Chaurasia SS, Vasanji A, Qi JH, Klenotic PA, Cutler A, et al. Cross-Talk Between Vascular Endothelial Growth Factor and Matrix Metalloproteinases in the Induction of Neovascularization In Vivo. Am J Pathol (2010) 176(1):496-503. doi: 10.2353/ajpath.2010.080642

66. Tamura R, Tanaka T, Akasaki Y, Murayama Y, Yoshida K, Sasaki H. The Role of Vascular Endothelial Growth Factor in the Hypoxic and Immunosuppressive Tumor Microenvironment: Perspectives for Therapeutic Implications. Med Oncol (Northwood London England) (2019) 37(1):2. doi: 10.1007/s12032-0191329-2

67. Koutsimpelas D, Bjelopavlovic M, Yetis R, Frauenknecht K, Adryan B, Schmidtmann I, et al. The VEGF/VEGF-R Axis in Sporadic Vestibular Schwannomas Correlates With Irradiation and Disease Recurrence. Orl J Otorhinolaryngol Head Neck Surg (2012) 74(6):330-8. doi: 10.1159/ 000346238

68. Alanin MC, Klausen C, Caye-Thomasen P, Thomsen C, Fugleholm K, Poulsgaard L, et al. The Effect of Bevacizumab on Vestibular Schwannoma Tumour Size and Hearing in Patients With Neurofibromatosis Type 2. Eur Arch Otorhinolaryngol (2015) 272(12):3627-33. doi: 10.1007/s00405-014-3398-3

69. Gao X, Zhao YC, Stemmer-Rachamimov AO, Liu H, Huang PG, Chin SM, et al. Anti-VEGF Treatment Improves Neurological Function and Augments Radiation Response in NF2 Schwannoma Model. Proc Natl Acad Sci USA (2015) 112(47):14676-81. doi: 10.1073/pnas.1512570112

70. Yi D, Kuo SZ, Zheng H, Abhold EL, Brown CM, Doherty JK, et al. Activation of PDGFR and EGFR Promotes the Acquisition of a Stem Cell-Like 
Phenotype in Schwannomas. Otol Neurotol (2012) 33(9):1640-7. doi: 10.1097/MAO.0b013e31826a540d

71. Fredriksson L, Li H, Eriksson U. The PDGF Family: Four Gene Products Form Five Dimeric Isoforms. Cytokine Growth Factor Rev (2004) 15(4):197204. doi: 10.1016/j.cytogfr.2004.03.007

72. Yener U, Avsar T, Akgun E, Seker A, Bayri Y, Kilic T. Assessment of Antiangiogenic Effect of Imatinib Mesylate on Vestibular Schwannoma Tumors Using In Vivo Corneal Angiogenesis Assay Laboratory Investigation. J Neurosurg (2012) 117(4):697-704. doi: 10.3171/2012.6.Jns112263

73. Thomas KA, Gimenezgallego G. Fibroblast Growth-Factors - BroadSpectrum Mitogens With Potent Angiogenic Activity. Trends Biochem Sci (1986) 11(2):81-4. doi: 10.1016/0968-0004(86)90271-9

74. Labanca E, Vazquez ES, Corn PG, Roberts JM, Wang F, Logothetis CJ, et al. Fibroblast Growth Factors Signaling in Bone Metastasis. Endocr Relat Cancer (2020) 27(7):R255-65. doi: 10.1530/erc-19-0472

75. Dilwali S, Lysaght A, Roberts D, Barker FG, McKenna MJ, Stankovic KM. Sporadic Vestibular Schwannomas Associated With Good Hearing Secrete Higher Levels of Fibroblast Growth Factor 2 Than Those Associated With Poor Hearing Irrespective of Tumor Size. Otol Neurotol (2013) 34(4):74854. doi: 10.1097/MAO.0b013e31828048ec

76. Plotkin SR, Duda DG, Muzikansky A, Allen J, Blakeley J, Rosser T, et al. Multicenter, Prospective, Phase II and Biomarker Study of High-Dose Bevacizumab as Induction Therapy in Patients With Neurofibromatosis Type 2 and Progressive Vestibular Schwannoma. J Clin Oncol (2019) 37 (35):3446-54. doi: 10.1200/jco.19.01367

77. Weerda HG, Gamberger TI, Siegner A, Gjuric M, Tamm ER. Effects of Transforming Growth Factor- $B 1$ and Basic Fibroblast Growth Factor on Proliferation of Cell Cultures Derived From Human Vestibular Nerve Schwannoma. Acta Otolaryngol (1998) 118(3):337-43. doi: 10.1080/ 00016489850183412

78. Ahmad ZK, Brown CM, Cueva RA, Ryan AF, Doherty JK. ErbB Expression, Activation, and Inhibition With Lapatinib and Tyrphostin (AG825) in Human Vestibular Schwannomas. Otol Neurotol (2011) 32(5):841-7. doi: 10.1097/MAO.0b013e31821f7d88

79. Bush ML, Burns SS, Oblinger J, Davletova S, Chang L-S, Welling DB, et al. Treatment of Vestibular Schwannoma Cells With ErbB Inhibitors. Otol Neurotol (2012) 33(2):244-57. doi: 10.1097/MAO.0b013e31823e287f

80. Clark JJ, Provenzano M, Diggelmann HR, Xu N, Hansen SS, Hansen MR. The ErbB Inhibitors Trastuzumab and Erlotinib Inhibit Growth of Vestibular Schwannoma Xenografts in Nude Mice: A Preliminary Study. Otol Neurotol (2008) 29(6):846-53. doi: 10.1097/MAO.0b013e31817f7398

81. Fuse MA, Dinh CT, Vitte J, Kirkpatrick J, Mindos T, Plati SK, et al. Preclinical Assessment of MEK1/2 Inhibitors for Neurofibromatosis Type 2-Associated Schwannomas Reveals Differences in Efficacy and Drug Resistance Development. Neuro Oncol (2019) 21(4):486-97. doi: 10.1093/ neuonc/noz002

82. Zinatizadeh MR, Momeni SA, Zarandi PK, Chalbatani GM, Dana H, Mirzaei HR, et al. The Role and Function of Ras-Association Domain Family in Cancer: A Review. Genes Dis (2019) 6(4):378-84. doi: 10.1016/j.gendis. 2019.07.008

83. Agnihotri S, Gugel I, Remke M, Bornemann A, Pantazis G, Mack SC, et al. Gene-Expression Profiling Elucidates Molecular Signaling Networks That Can Be Therapeutically Targeted in Vestibular Schwannoma. J Neurosurg (2014) 121(6):1434-45. doi: 10.3171/2014.6.jns131433

84. Slack-Davis JK, Eblen ST, Zecevic M, Boerner SA, Tarcsafalvi A, Diaz HB, et al. PAKI Phosphorylation of MEK1 Regulates Fibronectin-Stimulated MAPK Activation. J Cell Biol (2003) 162(2):281-91. doi: 10.1083/ jcb.200212141

85. Li WQ, Chong HR, Guan KL. Function of the Rho Family GTPases in RasStimulated Raf Activation. J Biol Chem (2001) 276(37):34728-37. doi: $10.1074 /$ jbc.M103496200

86. Morrison H, Sperka T, Manent J, Giovannini M, Ponta H, Herrlich P. Merlin/neurofibromatosis Type 2 Suppresses Growth by Inhibiting the Activation of Ras and Rac. Cancer Res (2007) 67(2):520-7. doi: 10.1158/ 0008-5472.Can-06-1608

87. Flaiz C, Chernoff J, Ammoun S, Peterson JR, Hanemann CO. PAK Kinase Regulates Rac GTPase and Is a Potential Target in Human Schwannomas. Exp Neurol (2009) 218(1):137-44. doi: 10.1016/j.expneurol.2009.04.019
88. Mercado-Pimentel ME, Miller C, Rolph DN, Villalobos EF, Dunn AM, Mohan PM, et al. Inhibiting P21-Activated Kinase Induces Cell Death in Vestibular Schwannoma and Meningioma via Mitotic Catastrophe. Otol Neurotol (2017) 38(1):139-46. doi: 10.1097/mao.0000000000001247

89. Yang PZ, Sun DZ, Jiang F. Ailanthone Promotes Human Vestibular Schwannoma Cell Apoptosis and Autophagy by Downregulation of miR21. Oncol Res (2018) 26(6):941-8. doi: 10.3727/096504018x15149775533331

90. Riecken LB, Zoch A, Wiehl U, Reichert S, Scholl I, Cui Y, et al. CPI-17 Drives Oncogenic Ras Signaling in Human Melanomas via Ezrin-Radixin-Moesin Family Proteins. Oncotarget (2016) 7(48):78242-54. doi: 10.18632/ oncotarget.12919

91. Cui Y, Groth S, Troutman S, Carlstedt A, Sperka T, Riecken LB, et al. The NF2 Tumor Suppressor Merlin Interacts With Ras and RasGAP, Which may Modulate Ras Signaling. Oncogene (2019) 38(36):6370-81. doi: 10.1038/ s41388-019-0883-6

92. Sperka T, Geissler KJ, Merkel U, Scholl I, Rubio I, Herrlich P, et al. Activation of Ras Requires the ERM-Dependent Link of Actin to the Plasma Membrane. PloS One (2011) 6(11):14. doi: 10.1371/journal.pone.0027511

93. Li Y, Zhou H, Li F, Chan SW, Lin Z, Wei Z, et al. Angiomotin BindingInduced Activation of Merlin/NF2 in the Hippo Pathway. Cell Res (2015) 25 (7):801-17. doi: 10.1038/cr.2015.69

94. Reginensi A, Enderle L, Gregorieff A, Johnson RL, Wrana JL, McNeill H. A Critical Role for NF2 and the Hippo Pathway in Branching Morphogenesis. Nat Commun (2016) 7:12309. doi: 10.1038/ncomms12309

95. Boin A, Couvelard A, Couderc C, Brito I, Filipescu D, Kalamarides M, et al. Proteomic Screening Identifies a YAP-Driven Signaling Network Linked to Tumor Cell Proliferation in Human Schwannomas. Neuro Oncol (2014) 16 (9):1196-209. doi: 10.1093/neuonc/nou020

96. Cooper J, Xu Q, Zhou L, Pavlovic M, Ojeda V, Moulick K, et al. Combined Inhibition of NEDD8-Activating Enzyme and mTOR Suppresses NF2 LossDriven Tumorigenesis. Mol Cancer Ther (2017) 16(8):1693-704. doi: 10.1158/1535-7163.mct-16-0821

97. Jiang XJ, Wang J, Deng XY, Xiong F, Zhang SS, Gong ZJ, et al. The Role of Microenvironment in Tumor Angiogenesis. J Exp Clin Cancer Res (2020) 39 (1):19. doi: 10.1186/s13046-020-01709-5

98. Wei F, Wang D, Wei JY, Tang NW, Tang L, Xiong F, et al. Metabolic Crosstalk in the Tumor Microenvironment Regulates Antitumor Immunosuppression and Immunotherapy Resisitance. Cell Mol Life Sci (2021) 78(1):173-93. doi: 10.1007/s00018-020-03581-0

99. Lai S, Huang L, Luo S, Liu Z, Dong J, Wang L, et al. Systemic Inflammatory Indices Predict Tumor Response to Neoadjuvant Chemoradiotherapy for Locally Advanced Rectal Cancer. Oncol Lett (2020) 20(3):2763-70. doi: 10.3892/ol.2020.11812

100. Sawada R, Akiyoshi T, Kitagawa Y, Hiyoshi Y, Mukai T, Nagasaki T, et al. Systemic Inflammatory Markers Combined With Tumor-Infiltrating Lymphocyte Density for the Improved Prediction of Response to Neoadjuvant Chemoradiotherapy in Rectal Cancer. Ann Surg Oncol (2021). doi: 10.1245/s10434-021-09975-z. in press.

101. de Vries M, Hogendoorn PCW, Briaire-de Bruyn I, Malessy MJA, van der Mey AGL. Intratumoral Hemorrhage, Vessel Density, and the Inflammatory Reaction Contribute to Volume Increase of Sporadic Vestibular Schwannomas. Virchows Arch (2012) 460(6):629-36. doi: 10.1007/s00428-012-1236-9

102. Han JH, Baek KH, Lee YW, Hur YK, Kim HJ, Moon IS. Comparison of Clinical Characteristics and Surgical Outcomes of Cystic and Solid Vestibular Schwannomas. Otol Neurotol (2018) 39(5):E381-6. doi: 10.1097/mao. 0000000000001813

103. Motolani A, Martin M, Sun MY, Lu T. Phosphorylation of the Regulators, a Complex Facet of NF-Kappa B Signaling in Cancer. Biomolecules (2021) 11 (1):13. doi: 10.3390/biom 11010015

104. Pereira SG, Oakley F. Nuclear Factor-Kappa B1: Regulation and Function. Int $J$ Biochem Cell Biol (2008) 40(8):1425-30. doi: 10.1016/j.biocel.2007.05.004

105. Karin M, Delhase M. The I Kappa B Kinase (IKK) and NF-Kappa B: Key Elements of Proinflammatory Signalling. Semin Immunol (2000) 12(1):8598. doi: $10.1006 / \mathrm{smim} .2000 .0210$

106. Sun SC. The Noncanonical NF-Kappa B Pathway. Immunol Rev (2012) 246:125-40. doi: 10.1111/j.1600-065X.2011.01088.x

107. Hoesel B, Schmid JA. The Complexity of NF-kb Signaling in Inflammation and Cancer. Mol Cancer (2013) 12(1):86. doi: 10.1186/1476-4598-12-86 
108. Gehlhausen JR, Hawley E, Wahle BM, He YZ, Edwards D, Rhodes SD, et al. A Proteasome-Resistant Fragment of NIK Mediates Oncogenic NF-Kappa B Signaling in Schwannomas. Hum Mol Genet (2019) 28(4):572-83. doi: $10.1093 / \mathrm{hmg} / \mathrm{ddy} 361$

109. Ahmad I, Yue WY, Fernando A, Clark JJ, Woodson EA, Hansen MR. P75 (NTR) Is Highly Expressed in Vestibular Schwannomas and Promotes Cell Survival by Activating Nuclear Transcription Factor Kappa B. Glia (2014) 62 (10):1699-712. doi: 10.1002/glia.22709

110. Behling F, Ries V, Skardelly M, Gepfner-Tuma I, Schuhmann M, Ebner FH, et al. COX2 Expression Is Associated With Proliferation and Tumor Extension in Vestibular Schwannoma But Is Not Influenced by Acetylsalicylic Acid Intake. Acta Neuropathol Commun (2019) 7:105. doi: 10.1186/s40478-019-0760-0

111. Xu J, Zhang Y, Shi Y, Yin D, Dai P, Zhao W, et al. Identification of Predictive Proteins and Biological Pathways for the Tumorigenicity of Vestibular Schwannoma by Proteomic Profiling. Proteomics Clin Appl (2019) 13 (5):1800175. doi: 10.1002/prca.201800175

112. Gong ZX, Huang WG, Wang BY, Liang N, Long SK, Li WJ, et al. Interplay Between Cyclooxygenase-2 and microRNAs in Cancer. Mol Med Rep (2021) 23(5):1-10. doi: 10.3892/mmr.2021.11986

113. Davila-Gonzalez D, Chang JC, Billiar TR. NO and COX2: Dual Targeting for Aggressive Cancers. Proc Natl Acad Sci USA (2017) 114(52):13591-3. doi: 10.1073/pnas.1717440114

114. Goradel NH, Najafi M, Salehi E, Farhood B, Mortezaee K. Cyclooxygenase-2 in Cancer: A Review. J Cell Physiol (2019) 234(5):5683-99. doi: 10.1002/ jcp. 27411

115. Montezuma MAP, Fonseca FP, Benites BM, Soares CD, do Amaral-Silva GK, de Almeida OP, et al. COX-2 as a Determinant of Lower Disease-Free Survival for Patients Affected by Ameloblastoma. Pathol Res Pract (2018) 214 (6):907-13. doi: 10.1016/j.prp.2018.03.014

116. Ma J, Cai ZL, Wei HL, Liu XL, Zhao QL, Zhang T. The Anti-Tumor Effect of Aspirin: What We Know and What We Expect. BioMed Pharmacother (2017) 95:656-61. doi: 10.1016/j.biopha.2017.08.085

117. Wang P, Shen YP, Zhao L. Chitosan Nanoparticles Loaded With Aspirin and 5-Fluororacil Enable Synergistic Antitumour Activity Through the Modulation of NF-Kappa B/COX-2 Signalling Pathway. IET Nanobiotechnol (2020) 14(6):479-84. doi: 10.1049/iet-nbt.2020.0002

118. Jiang W, Yan Y, Chen MY, Luo GY, Hao JJ, Pan JJ, et al. Aspirin Enhances the Sensitivity of Colon Cancer Cells to Cisplatin by Abrogating the Binding of NF-Kappa B to the COX-2 Promoter. Aging-US (2020) 12(1):611-27. doi: 10.18632/aging.102644

119. Kandathil CK, Dilwali S, Wu CC, Ibrahimov M, McKenna MJ, Lee H, et al. Aspirin Intake Correlates With Halted Growth of Sporadic Vestibular Schwannoma In Vivo. Otol Neurotol (2014) 35(2):353-7. doi: 10.1097/ mao.0000000000000189

120. Kandathil CK, Cunnane ME, McKenna MJ, Curtin HD, Stankovic KM. Correlation Between Aspirin Intake and Reduced Growth of Human Vestibular Schwannoma: Volumetric Analysis. Otol Neurotol (2016) 37 (9):1428-34. doi: 10.1097/mao.0000000000001180

121. Ignacio KHD, Espiritu AI, Diestro JDB, Chan KI, Dmytriw AA, Omar AT. Efficacy of Aspirin for Sporadic Vestibular Schwannoma: A Meta-Analysis. Neurol Sci (2021). doi: 10.1007/s10072-021-05193-3. in press.

122. Mehraj U, Qayoom H, Mir MA. Prognostic Significance and Targeting Tumor-Associated Macrophages in Cancer: New Insights and Future Perspectives. Breast Cancer (2021) 28(3):1-17. doi: 10.1007/s12282-02101231-2

123. Huang YC, Feng ZP. The Good and Bad of Microglia/Macrophages: New Hope in Stroke Therapeutics. Acta Pharmacol Sin (2013) 34(1):6-7. doi: 10.1038 /aps.2012.178

124. Rogers TL, Holen I. Tumour Macrophages as Potential Targets of Bisphosphonates. J Trans Med (2011) 9:17. doi: 10.1186/1479-5876-9-177

125. Cao LL, Che XF, Qiu XS, Li Z, Yang BW, Wang S, et al. M2 Macrophage Infiltration Into Tumor Islets Leads to Poor Prognosis in Non-Small-Cell Lung Cancer. Cancer Manage Res (2019) 11:6125-38. doi: 10.2147/cmar.S199832

126. Hu H, Tu WZ, Chen YG, Zhu M, Jin H, Huang T, et al. The Combination of PKM2 Overexpression and M2 Macrophages Infiltration Confers a Poor Prognosis for PDAC Patients. J Cancer (2020) 11(8):2022-31. doi: 10.7150/ jca.38981
127. Lewis D, Donofrio CA, O'Leary C, Li K-L, Zhu X, Williams R, et al. The Microenvironment in Sporadic and Neurofibromatosis Type II-Related Vestibular Schwannoma: The Same Tumor or Different? A Comparative Imaging and Neuropathology Study. J Neurosurg (2021) 134(5):1419-29. doi: 10.3171/2020.3.Jns193230

128. Bi WL, Gupta S, Mei Y, Al Abdulmohsen S, Larsen AG, Unadkat P, et al. Immunophenotype of Vestibular Schwannomas. Otol Neurotol (2020) 41 (10):E1290-E6. doi: 10.1097/mao.0000000000002782

129. Chow MT, Moeller A, Smyth MJ. Inflammation and Immune Surveillance in Cancer. Semin Cancer Biol (2012) 22(1):23-32. doi: 10.1016/j.semcancer. 2011.12.004

130. Templeton AJ, McNamara MG, Seruga B, Vera-Badillo FE, Aneja P, Ocana A, et al. Prognostic Role of Neutrophil-To-Lymphocyte Ratio in Solid Tumors: A Systematic Review and Meta-Analysis. J Natl Cancer Inst (2014) 106(6):dju124. doi: 10.1093/jnci/dju124

131. Tikka T, Yiannakis CP, Stapleton E, Locke R, Crowther JA, Taylor WAS, et al. Spontaneous Vestibular Schwannoma Regression: A Case-Control Study. Otol Neurotol (2018) 39(10):E1118-24. doi: 10.1097/mao.0000000000001962

132. Ying SY, Lin SL. Current Perspectives in Intronic Micro RNAs (miRNAs). J BioMed Sci (2006) 13(1):5-15. doi: 10.1007/s11373-005-9036-8

133. Lei YH, Guo P, Li XG, Zhang YY, Du T. Identification of Differentially Expressed miRNAs and mRNAs in Vestibular Schwannoma by Integrated Analysis. BioMed Res Int (2019) 2019:10. doi: 10.1155/2019/7267816

134. Saydam O, Senol O, Wurdinger T, Mizrak A, Ozdener GB, StemmerRachamimov AO, et al. miRNA-7 Attenuation in Schwannoma Tumors Stimulates Growth by Upregulating Three Oncogenic Signaling Pathways. Cancer Res (2011) 71(3):852-61. doi: 10.1158/0008-5472.Can-10-1219

135. Zhao X, Hou YX, Tuo ZZ, Wei FM. Application Values of miR-194 and miR29 in the Diagnosis and Prognosis of Gastric Cancer. Exp Ther Med (2018) 15 (5):4179-84. doi: 10.3892/etm.2018.5931

136. Liu QL, Geng PS, Shi LY, Wang Q, Wang PL. miR-29 Promotes Osteosarcoma Cell Proliferation and Migration by Targeting PTEN. Oncol Lett (2019) 17(1):883-90. doi: 10.3892/ol.2018.9646

137. Jiang HS, Zhang G, Wu JH, Jiang CP. Diverse Roles of miR-29 in Cancer (Review). Oncol Rep (2014) 31(4):1509-16. doi: 10.3892/or.2014.3036

138. Strong AMP, Setaluri V, Spiegelman VS. microRNA-340 as a Modulator of RAS-RAF-MAPK Signaling in Melanoma. Arch Biochem Biophys (2014) 563:118-24. doi: 10.1016/j.abb.2014.07.012

139. Rong JP, Xu L, Hu YY, Liu F, Yu YR, Guo HY, et al. Inhibition of Let-7b-5p Contributes to an Anti-Tumorigenic Macrophage Phenotype Through the SOCS1/STAT Pathway in Prostate Cancer. Cancer Cell Int (2020) 20(1):15. doi: 10.1186/s12935-020-01563-7

140. Peng H, Yang H, Xiang X, Li SG. MicroRNA-221 Participates in Cerebral Ischemic Stroke by Modulating Endothelial Cell Function by Regulating the PTEN/PI3K/AKT Pathway. Exp Ther Med (2020) 19(1):443-50. doi: 10.3892/etm.2019.8263

141. Sucheta, Kataria SP, Malik S, Yadav R, Kapil R, Sen R. Histomorphological and Morphometric Evaluation of Microvessel Density in Nodal NonHodgkin Lymphoma Using CD34 and CD105. J Lab Phys (2021) 22(9):7. doi: 10.1055/s-0041-1726569

142. Burghardt I, Ventura E, Weiss T, Schroeder JJ, Seystahl K, Zielasek C, et al. Endoglin and TGF-Beta Signaling in Glioblastoma. Cell Tissue Res (2021) 384(3):613-24. doi: 10.1007/s00441-020-03323-5

143. Mo FZ, Duan SL, Jiang XB, Yang XM, Hou XQ, Shi W, et al. NanobodyBased Chimeric Antigen Receptor T Cells Designed by CRISPR/Cas9 Technology for Solid Tumor Immunotherapy. Signal Transduct Target Ther (2021) 6(1):12. doi: 10.1038/s41392-021-00462-1

144. Liu YM, Paauwe M, Nixon AB, Hawinkels L. Endoglin Targeting: Lessons Learned and Questions That Remain. Int J Mol Sci (2021) 22(1):15. doi: $10.3390 /$ ijms 22010147

145. de Vries I, Schmitt H, Lenarz T, Prenzler N, Alvi S, Staecker H, et al. Detection of BDNF-Related Proteins in Human Perilymph in Patients With Hearing Loss. Front Neurosci (2019) 13:214. doi: 10.3389/fnins.2019.00214

146. Fields GB. Mechanisms of Action of Novel Drugs Targeting AngiogenesisPromoting Matrix Metalloproteinases. Front Immunol (2019) 10:1278. doi: 10.3389/fimmu.2019.01278

147. Xu JH, Ma J, Shi YX, Yin DM, Zhang Y, Dai PD, et al. Differential Protein Expression Between Cystic and Solid Vestibular Schwannoma Using 
Tandem Mass Tag-Based Quantitative Proteomic Analysis. Proteomics Clin Appl (2020) 14(4):1900112. doi: 10.1002/prca.201900112

148. Moon KS, Jung S, Seo SK, Jung TY, Kim IY, Ryu HH, et al. Cystic Vestibular Schwannomas: A Possible Role of Matrix Metalloproteinase-2 in Cyst Development and Unfavorable Surgical Outcome. J Neurosurg (2007) 106 (5):866-71. doi: 10.3171/jns.2007.106.5.866

149. Oria VO, Lopatta P, Schilling O. The Pleiotropic Roles of ADAM9 in the Biology of Solid Tumors. Cell Mol Life Sci (2018) 75(13):2291-301. doi: 10.1007/s00018-018-2796-x

150. Mygind KJ, Schwarz J, Sahgal P, Ivaska J, Kveiborg M. Loss of ADAM9 Expression Impairs Beta 1 Integrin Endocytosis, Focal Adhesion Formation and Cancer Cell Migration. J Cell Sci (2018) 131(1):jcs205393. doi: 10.1242/ jcs. 205393

151. Mygind KJ, Storiko T, Freiberg ML, Samsoe-Petersen J, Schwarz J, Andersen OM, et al. Sorting Nexin 9 (SNX9) Regulates Levels of the Transmembrane ADAM9 at the Cell Surface. J Biol Chem (2018) 293(21):8077-88. doi: 10.1074/jbc.RA117.001077

152. Chang L, Gong FC, Cai HF, Li ZH, Cui YB. Combined RNAi Targeting Human Stat3 and ADAM9 as Gene Therapy for Non-Small Cell Lung Cancer. Oncol Lett (2016) 11(2):1242-50. doi: 10.3892/ol.2015.4018

153. Chen WL, Lu Q, Li SY, Zhang XY, Xue XH. microRNA-1298 Inhibits the Malignant Behaviors of Breast Cancer Cells via Targeting ADAM9. Biosci Rep (2020) 40:12. doi: 10.1042/bsr20201215

154. Gol MAK, Lund TC, Levine SC, Adams ME. Quantitative Proteomics of Vestibular Schwannoma Cerebrospinal Fluid: A Pilot Study. Otolaryngol Head Neck Surg (2016) 154(5):902-6. doi: 10.1177/0194599816630544

155. Xiao F, Lv SG, Zong ZT, Wu L, Tang XP, Kuang W, et al. Cerebrospinal Fluid Biomarkers for Brain Tumor Detection: Clinical Roles and Current Progress. Am J Transl Res (2020) 12(4):1379-96.

156. Mattox AK, Yan H, Bettegowda C. The Potential of Cerebrospinal FluidBased Liquid Biopsy Approaches in CNS Tumors. Neuro Oncol (2019) 21 (12):1509-18. doi: 10.1093/neuonc/noz156

157. Bai Y, Liu YJ, Wang H, Xu Y, Stamenkovic I, Yu Q. Inhibition of the HyaluronanCD44 Interaction by Merlin Contributes to the Tumor-Suppressor Activity of Merlin. Oncogene (2007) 26(6):836-50. doi: 10.1038/sj.onc.1209849

158. de Vries M, Briaire-de Bruijn I, Malessy MJ, de Bruïne SF, van der Mey AG, Hogendoorn PC. Tumor-Associated Macrophages Are Related to Volumetric Growth of Vestibular Schwannomas. Otol Neurotol (2013) 34 (2):347-52. doi: 10.1097/MAO.0b013e31827c9fbf

159. Neff BA, Voss SG, Allen C, Schroeder MA, Driscoll CLW, Link MJ, et al. Bioluminescent Imaging of Intracranial Vestibular Schwannoma Xenografts in NOD/SCID Mice. Otol Neurotol (2009) 30(1):105-11. doi: 10.1097/ MAO.0b013e31818b6cea

160. Bonne N-X, Vitte J, Chareyre F, Karapetyan G, Khankaldyyan V, Tanaka K, et al. An Allograft Mouse Model for the Study of Hearing Loss Secondary to Vestibular Schwannoma Growth. J Neurooncol (2016) 129(1):47-56. doi: 10.1007/s11060-016-2150-9

161. Szczupak M, Pena SA, Bracho O, Mei C, Bas E, Fernandez-Valle C, et al. Fluorescent Detection of Vestibular Schwannoma Using Intravenous Sodium Fluorescein In Vivo. Otol Neurotol (2021) 42(4):E503-11. doi: 10.1097/mao.0000000000002988
162. Helbing DL, Schulz A, Morrison H. Pathomechanisms in Schwannoma Development and Progression. Oncogene (2020) 39(32):5421-9. doi: 10.1038/s41388-020-1374-5

163. Lee HJ, Yang YJ, Jeong S, Lee JD, Choi SY, Jung DW, et al. Development of a Vestibular Schwannoma Xenograft Zebrafish Model for In Vivo Antitumor Drug Screening. Laryngoscope (2016) 126(12):E409-15. doi: 10.1002/ lary. 26043

164. Breun M, Martellotta DD, Leberle A, Nietzer S, Baur F, Ernestus R-I, et al. 3D In Vitro Test System for Vestibular Schwannoma. J Neurosci Methods (2020) 336:108633. doi: 10.1016/j.jneumeth.2020.108633

165. Wu L, Vasilijic S, Sun Y, Chen J, Landegger LD, Zhang Y, et al. Losartan Prevents Tumor-Induced Hearing Loss and Augments Radiation Efficacy in NF2 Schwannoma Rodent Models. Sci Transl Med (2021) 13(602):eabd4816. doi: 10.1126/scitranslmed.abd 4816

166. Meyer HJ, Leifels L, Hamerla G, Hohn AK, Surov A. Histogram Analysis Parameters Derived From Conventional T1-And T2-Weighted Images Can Predict Different Histopathological Features Including Expression of Ki67, EGFR, VEGF, HIF-1 Alpha, and P53 and Cell Count in Head and Neck Squamous Cell Carcinoma. Mol Imag Biol (2019) 21(4):740-6. doi: 10.1007/ s11307-018-1283-y

167. Shcherbakova DM, Baloban M, Emelyanov AV, Brenowitz M, Guo P, Verkhusha VV. Bright Monomeric Near-Infrared Fluorescent Proteins as Tags and Biosensors for Multiscale Imaging. Nat Commun (2016) 7:12405. doi: $10.1038 /$ ncomms 12405

168. Hessler M, Jalilian E, Xu Q, Reddy S, Horton L, Elkin K, et al. Melanoma Biomarkers and Their Potential Application for In Vivo Diagnostic Imaging Modalities. Int J Mol Sci (2020) 21(24):9583. doi: 10.3390/ijms21249583

169. Sewda K, Coppola D, Enkemann S, Yue B, Kim J, Lopez AS, et al. CellSurface Markers for Colon Adenoma and Adenocarcinoma. Oncotarget (2016) 7(14):17773-89. doi: 10.18632/oncotarget.7402

170. Morrison DR, Sorace AG, Hamilton E, Moore LS, Houson HA, Udayakumar $\mathrm{N}$, et al. Predicting Schwannoma Growth in a Tumor Model Using Targeted Imaging. Otol Neurotol (2021) 42(5):e615-23. doi: 10.1097/MAO. 0000000000003063

Conflict of Interest: The authors declare that the research was conducted in the absence of any commercial or financial relationships that could be construed as a potential conflict of interest.

Publisher's Note: All claims expressed in this article are solely those of the authors and do not necessarily represent those of their affiliated organizations, or those of the publisher, the editors and the reviewers. Any product that may be evaluated in this article, or claim that may be made by its manufacturer, is not guaranteed or endorsed by the publisher.

Copyright (๐ 2021 Zhang, Long, Ren, Huang, Zhong and Wang. This is an open-access article distributed under the terms of the Creative Commons Attribution License (CC BY). The use, distribution or reproduction in other forums is permitted, provided the original author(s) and the copyright owner(s) are credited and that the original publication in this journal is cited, in accordance with accepted academic practice. No use, distribution or reproduction is permitted which does not comply with these terms. 